REVIEW ARTICLE

\title{
Proteolytic Cleavage of Polyglutamine Disease-Causing Proteins: Revisiting the Toxic Fragment Hypothesis
}

20

Carlos A. Matos ${ }^{1,2}$, Luís Pereira de Almeida ${ }^{1,3, *}$ and Clévio Nóbrega ${ }^{4}$

${ }^{I}$ CNC - Center for Neuroscience and Cell Biology, University of Coimbra, Coimbra, Portugal; ${ }^{2}$ Institute for Interdisciplinary Research, University of Coimbra, Coimbra, Portugal; ${ }^{3}$ Faculty of Pharmacy, University of Coimbra, Coimbra, Portugal; ${ }^{4}$ Department of Biomedical Sciences and Medicine, University of Algarve, 8005-139 Faro, Portugal; Center for Biomedical Research (CBMR), University of Algarve, 8005-139 Faro, Portugal

\section{A R T I C L E H IS T ORY}

Received: November 2, 2016

Accepted: December 26, 2016 DOI: $10.2174 / 1381612822666161227$
121912

\begin{abstract}
Proteolytic cleavage has been implicated in the pathogenesis of diverse neurodegenerative diseases involving abnormal protein accumulation. Polyglutamine diseases are a group of nine hereditary disorders caused by an abnormal expansion of repeated glutamine tracts contained in otherwise unrelated proteins. When expanded, these proteins display toxic properties and are prone to aggregate, but the mechanisms responsible for the selective neurodegeneration observed in polyglutamine disease patients are still poorly understood. It has been suggested that the neuronal toxicity of polyglutamine-expanded proteins is associated with the production of deleterious protein fragments.

This review aims at discussing the involvement of proteolytic cleavage in the six types of spinocerebellar ataxia caused by polyglutamine expansion of proteins. The analysis takes into detailed consideration evidence concerning fragment detection and the mechanisms of fragment toxicity.

Current evidence suggests that the proteins involved in spinocerebellar ataxia types 3, 6 and 7 give rise to stable proteolytic fragments. Fragments carrying polyglutamine expansions display increased tendency to aggregate and toxicity, comparing with their non-expanded counterparts or with the correspondent full-length expanded proteins. Data concerning spinocerebellar ataxia types 1,2 and 17 is still scarce, but available results afford further investigation.

Available literature suggests that proteolytic cleavage of expanded polyglutamine-containing proteins enhances toxicity in disease-associated contexts and may constitute an important step in the pathogenic cascade of polyglutamine diseases. Countering protein fragmentation thus presents itself as a promising therapeutic aim.
\end{abstract}

Keywords: Neurodegenerative diseases, proteolytic cleavage, polyglutamine diseases, spinocerebellar ataxia, machado-joseph disease, toxic fragments, ataxin-3, voltage-dependent P/Q-type calcium channel subunit alpha-1A, ataxin-7.

\section{PROTEOLYTIC CLEAVAGE AND NEURODEGENERA- TIVE DISEASES}

After the synthesis of a polypeptide sequence through the covalent attachment of successive amino acid residues, a protein is usually subjected to further modifications before becoming apt to fulfill its particular role in a cell. Post-translational modifications frequently consist in the covalent attachment of additional chemical groups (such as phosphate or acetyl), proteins (such as ubiquitin) or oligosaccharides, catalyzed by specialized enzymes, often in a reversible way. Other types of protein processing involve the removal of parts of the polypeptide sequence by means of proteolytic cleavage, i.e., the separation of peptide bonds existing between amino acids. This irreversible modification is catalyzed by proteases and is involved in the activation and inactivation of proteins implicated in diverse physiologic functions, such as blood coagulation, digestion, cell cycle progression, cell death, as well as in the production of hormones. Proteolysis is also tightly implicated in protein turnover regulation, by virtue of its central role in protein degradation.

Alterations in proteolytic processing have been associated with neurodegenerative diseases ever since peptide fragments resulting from the amyloid precursor protein (APP) were observed to amass in the brain of Alzheimer's disease (AD) patients [1]. APP is a

*Address correspondence to this author at the Center for Neuroscience \& Cell Biology and Faculty of Pharmacy, University of Coimbra, Rua Larga, Faculdade de Medicina, Pólo I, $1^{\circ}$ andar, 3004-504 Coimbra, Portugal; Tel: 3519663374 82; Fax: 351239853 409; E-mail: luispa@cnc.uc.pt plasma membrane protein found in neurons that is proteolyzed by a series of secretase enzymes, producing the amyloid beta peptide. This APP-derived fragment forms the hallmark amyloid plaques of $\mathrm{AD}$ and is believed to possess intrinsic toxic properties related with its propensity to aggregate and form oligomers [2]. APP fragment is regarded as an important step in AD pathogenesis [3]. Proteolytic cleavage of tau has also been proposed to participate in the aggregation pathway of this protein and the consequent formation of neurofibrillary tangles in $\mathrm{AD}$ and other neurodegenerative disorders involving tau accumulation $[4,5]$. Neuronal aggregation of alphasynuclein in Parkinson's disease and other pathologies has been related to the truncation of the protein $[6,7]$. These and other observations suggest that proteolytic cleavage may be a common motive in the pathogenic mechanisms responsible for neurologic diseases involving accumulation of protein species that are believed to be prone to misfold and aggregate [8].

Polyglutamine (polyQ) diseases are a group of untreatable and progressive neurodegenerative disorders caused by a common mutation in otherwise unrelated genes: an abnormal expansion of a CAG repeat sequence occurring in the codifying region $[9,10]$. Since the CAG trinucleotide codifies the amino acid glutamine, protein products are translated as polypeptide sequences bearing a sequence of expanded glutamine residues (Table 1). The group currently includes Huntington's disease (HD), dentatorubralpallidoluysian atrophy (DRPLA), spinal and bulbar muscular atrophy (SBMA) and six types of autosomal dominant types of spinocerebellar ataxia (SCA): spinocerebellar ataxia type 1, 2, 3, 6, 7 
Table 1. Fragments of polyglutamine disease-associated proteins.

\begin{tabular}{|c|c|c|c|c|c|c|}
\hline Disease & Gene & Protein & Putative functions & $\begin{array}{c}\text { Pathogenic CAG repeat size } \\
\text { (relative polyQ sequence position) }\end{array}$ & $\begin{array}{l}\text { Fragment detec- } \\
\text { tion }\end{array}$ & $\begin{array}{l}\text { Deleterious properties of the frag- } \\
\text { ments }\end{array}$ \\
\hline HD & HTT & huntingtin & $\begin{array}{l}\text { Transport, signalling, } \\
\text { transcription }\end{array}$ & $\begin{array}{c}36-121 \\
\text { (N-terminal) }\end{array}$ & $\begin{array}{l}\text { In cells, animal } \\
\text { models and humans }\end{array}$ & $\begin{array}{l}\text { Altered subcellular localization, } \\
\text { increased aggregation and cytotoxicity }\end{array}$ \\
\hline SBMA & $A R$ & $\begin{array}{l}\text { androgen } \\
\text { receptor }\end{array}$ & $\begin{array}{l}\text { Steroid hormone } \\
\text { signalling and tran- } \\
\text { scription }\end{array}$ & $\begin{array}{c}38-62 \\
\text { (N-terminal) }\end{array}$ & $\begin{array}{l}\text { In cells, animal } \\
\text { models and humans }\end{array}$ & $\begin{array}{l}\text { Altered subcellular localization, } \\
\text { increased aggregation and cytotoxicity }\end{array}$ \\
\hline DRPLA & $A T N 1$ & atrophin-1 & Transcription & $\begin{array}{c}\text { 49-88 } \\
\text { (Medial) }\end{array}$ & $\begin{array}{l}\text { In cells, animal } \\
\text { models and humans }\end{array}$ & $\begin{array}{l}\text { Altered subcellular localization, } \\
\text { increased aggregation and cytotoxicity }\end{array}$ \\
\hline SCA1 & $A T X N 1$ & ataxin-1 & Transcription & $\begin{array}{c}\text { 39-91 } \\
\text { (N-terminal) }\end{array}$ & In animal models & None reported \\
\hline SCA2 & $A T X N 2$ & ataxin-2 & RNA metabolism & $\begin{array}{c}32-200 \\
\text { (N-terminal) }\end{array}$ & cells and humans & None reported \\
\hline SCA3/MJD & $A T X N 3$ & ataxin-3 & $\begin{array}{l}\text { Ubiquitin signalling, } \\
\text { cytoskeleton organi- } \\
\text { zation and transcrip- } \\
\text { tion }\end{array}$ & $\begin{array}{r}45-87 \\
\text { (C-termin }\end{array}$ & $\begin{array}{l}\text { In cells, animal } \\
\text { models and humans }\end{array}$ & $\begin{array}{l}\text { Altered subcellular localization, } \\
\text { increased aggregation and cytotoxicity }\end{array}$ \\
\hline SCA6 & CACNAIA & Cav2.1 & $\begin{array}{l}\text { Voltage-dependent } \\
\text { calcium signalling }\end{array}$ & (C-terminal) & In cells and humans & $\begin{array}{l}\text { Altered subcellular localization, } \\
\text { increased aggregation and cytotoxicity }\end{array}$ \\
\hline SCA7 & $A T X N 7$ & ataxin-7 & Transcription & $\begin{array}{l}34-306 \\
(\mathrm{~N}-\text { terminal })\end{array}$ & $\begin{array}{l}\text { In cells, animal } \\
\text { models and humans }\end{array}$ & $\begin{array}{l}\text { Altered subcellular localization, } \\
\text { increased aggregation and cytotoxicity }\end{array}$ \\
\hline SCA17 & $T B P$ & TBP & Transcription & & In animal models & Increased aggregation \\
\hline
\end{tabular}

The table summarizes features of polyglutamine disease-causing proteins and the data relative to the putatively toxic fragments mentioned throughout the text.

Abreviativos: Cav2.1, voltage-dependent P/Q-type calcium channel subunit alpha-1A; DRPLA, dentatorubral-pallidoluysian atrophy; HD, Huntington's disease; MJD, MachadoJoseph disease; SBMA, spinal and bulbar muscular atrophy; SCA1, 2, 3, 6, 7, 17, spinocerebellas ataxia type 1, 2, 3, 6, 7 and 17; TBP, TATA-box-binding protein.

and 17 (SCA1, 2, 3, 6, 7, 17) [9, 11]. Every polyQ disease involves progressive neuronal demise that is restricted to selective populations of neurons, but the specific critical threshold of repeat number, the regions of the central nervous system that are affected and the associated clinical signs are characteristic of each disorder. Features generally shared by polyQ diseases include a) the existence of a positive correlation between the variable CAG repeat number and both the severity and precocity of symptoms; b) generational instability in CAG repeat number transmission, with a general tendency for an increase and the consequent anticipation of symptoms in successive generations; c) propensity for the protein products to aggregate and to constitute large intracellular multiprotein inclusions that are detected in patients' neuronal tissue, frequently in the cellular nucleus [10-15].

The molecular mechanisms responsible for neurodegeneration in polyQ disease patients are still largely unknown, but it has been suggested that alterations introduced to designated protein functions and/or molecular interactions as a consequence of polyQ expansion may underlie pathology [15-17]. However, in spite of possible specific traits that may explain the particularities of each disorder, the fact that the same type of mutation in otherwise unrelated genes and proteins leads to neurodegeneration has prompted researchers to look into polyQ diseases as a group, in a search for common disease mechanisms $[14,16,18]$. Though the formation of large inclusions has been generally excluded as a causative toxic change, aggregation is still envisioned as an important deleterious process $[15,19]$. The identity of the actually pathogenic species causing neurodegen- eration in polyQ diseases remains, to some extent, a mystery, but many attribute toxicity to the amyloid-like oligomeric intermediaries of the aggregation pathway [20]. Some cellular changes proposed to be a shared cause of degeneration include: a) transcriptional alterations; b) impaired axonal transport; c) abnormalities in neurotransmission; d) proteotoxic stress resulting from disruption of quality control systems; e) mitochondrial dysfunction, leading to oxidative stress and bioenergetic defects; f) dysregulation of intracellular calcium homeostasis; and g) impairment of DNA quality control systems $[15,18,20,21]$.

Results obtained in several experimental models have suggested that proteolytic cleavage of polyQ-containing proteins may be another common factor playing an important role in pathogenesis [2224]. Fragmentation may contribute to changes in the biochemical properties of the pathogenic protein species and thereby underlie deleterious changes in aggregation propensity, protein function, molecular interactions, subcellular localization and stability. The theory proposing that the toxicity of expanded polyQ-containing proteins is increased, or caused, by proteolytic processing and consequent formation of polyQ-containing fragments is referred to as the "toxic fragments hypothesis".

Huntingtin, the androgen receptor and atrophin-1, the proteins involved in HD, SBMA and DRPLA, respectively, have been demonstrated to produce detectable fragments in vitro [25], in cell cultures [26-28] as well as in animal disease models [29-32] and in human patients [29, 30, 33-36]. A vast body of research supports 
the importance of protein cleavage and fragment formation in the context of these diseases. Results from diverse reports have suggested that fragments originated by the disease-associated proteins are deleterious in cultured cells [26, 28, 37-39] and in animal models [40-42], are more toxic [43-45] and more prone to aggregate $[26,30,43,46,47]$ than their full-length counterparts, and suffer an abnormal translocation to the nucleus that may be connected with their increased toxicity [26, 28, 37, 46]. Although even the nonexpanded polyQ-carrying proteins appear to be susceptible to cleavage $[26,27,48]$, the polyQ-expanded forms of the pathogenic proteins have been occasionally observed to be more prone to proteolytic processing $[37,49,50]$ and the polyQ-expanded fragments are admitted to be more deleterious than the ones carrying no expansion $[28,37,39]$.

The current review focuses on the evidence connecting proteolytic cleavage and pathogenesis in the remaining polyQ diseases: the six types of SCAs caused by CAG expansion of the respective genes. PolyQ-associated SCAs are the most frequent forms of autosomal dominantly inherited cerebellar ataxia. Beyond the causative mutation, these diseases also share a collection of progressive cerebellar and non-cerebellar neurologic signs and a predominantly adult onset [9]. The fact that each of them also displays some unique features and is associated with proteins that have very distinct characteristics justifies a particularized look. This literature analysis starts with a comprehensive description of the role of proteolytic cleavage in SCA3, aiming at contextualizing this subject with some general aspects of polyQ toxicity. Attention then moves on to SCA6 and SCA7, and finally to the scarce proof available for SCA1, SCA2 and SCA17. The objective of this review is to give detailed information regarding a) the detection of protein fragments in human tissue and in different experimental systems; b) mapping of cleavage sites; c) putative enzymes involved in proteolysis; d) toxicity of fragments in patients and disease models; and e) the mechanisms mediating fragment toxicity.

\section{ATAXIN-3 AND SPINOCEREBELLAR ATAXIA TYPE 3}

Machado-Joseph disease (MJD), also generally known as spinocerebellar ataxia type 3 (SCA3), is the second most prevalent polyQ disease worldwide and the most common form of autosomal dominantly-inherited SCA, assuming particular relevance in Brazil, Portugal, the Netherlands, Germany, China and Japan $[13,51]$. The hallmark, progressive, cerebellar ataxia associated with the disease may be variously accompanied by pyramidal and extra-pyramidal signs, sensory deficits and parkinsonian features [52]. Neuronal demise associated with SCA3/MJD is regarded as mainly involving the cerebellum, the brainstem, the basal ganglia and the spinal cord, though recent evidence is indicative that it is more widespread than traditionally thought $[9,53,54]$. SCA3/MJD is often described as a late-onset disease, but symptoms in fact first manifest at a mean age of about 40 years [52].

The protein responsible for SCA3/MJD is ataxin-3 (atxn3), a deubiquitinase of still unclear biologic function that is believed to play a role in protein degradation, transcription regulation and cytoskeleton organization, codified by the $A T X N 3$ gene $[55,56]$. Still, to date no activity that would be specifically important for neuronal survival or functioning and that, when disturbed, could help explain the neuronal specificity of SCA3/MJD's degeneration profile has been described.

Structurally, atxn3 is a $40-43 \mathrm{kDa}$ protein (the canonical form has 364 amino acids) mainly composed by a structured N-terminal globular domain responsible for the enzymatic activity - the Josephin domain (JD) - and a more flexible C-terminal tail bearing the polyQ sequence of variable repeat number and length [57]. When expanded beyond the critical threshold of about 60 glutamines the protein leads to the development of SCA3/MJD (alleles with 45-59 glutamines display a variable penetrance) [52].
Although atxn3 is normally found both in the nucleus and the cytoplasm, in neurons the non-expanded protein is mainly cytoplasmic [58-60], while the polyQ-expanded form is known to amass in the form of nuclear inclusions, in affected and non-affected brain regions [60-62]. Nuclear localization of atxn3 is generally regarded as a factor contributing to the toxicity of the expanded form of the protein $[59,63,64]$. Cytoplasmic and axonal inclusions have also been recently described and related to $\mathrm{MJD} / \mathrm{SCA} 3$-associated neurodegeneration $[65,66]$.

\subsection{Detection of atxn3-Derived Fragments}

Reports involving Western blot probing of atxn3-containing protein samples occasionally highlight the detection of lower molecular weight species that react with atxn3-specific antibodies. Though it could be argued that such protein bands correspond to atxn3 species undergoing degradation, the repeated observation of bands of particular sizes and the way some of the lower-weight species detection is contingent upon protease activity manipulation attests their identity as "stable" proteolytic fragments of atxn3. The topology of these fragments is often inferred considering their reactivity against the antibodies used (antibodies recognizing particular atxn3 epitopes or N-/C-terminal tags) and, more infrequently, by mass spectrometry or Edman degradation [67, 68].

Studies exploring the proteolytic cleavage of atxn3 frequently report the detection of a major human expanded atxn3-derived species that migrates at about 34-37 kDa [69-74]. Antibody mapping reveals that this proteolytic fragment corresponds to a $\mathrm{C}$-terminal portion of the protein $[69-72,74]$. The cleavage event giving rise to this fragment seems to be biologically conserved, having been detected in Drosophila melanogaster [70], in mice [71-73], in mouse neuroblastoma (N2a) cells [75], in COS-7 cells [74], as well as in human patients [69]. The fragment contains the pathogenic polyQ stretch, being labelled by the polyQ-detecting $1 \mathrm{C} 2$ antibody $[69,71$, 72] and/or varying in size depending on the length of the polyQ region $[70,74]$. These variations admittedly account for the diversity in the molecular weights reported [70] and likely explain the reduced size of other fragments with similar topology, deriving from endogenous atxn3 (28 kDa, in COS-7 cells) [74] or transgenic non-expanded atxn3 (22 kDa, in transgenic flies) [70].

Fragments with different molecular sizes and/or other regional composition have been described, albeit more varyingly. Some of these species have been detected through in vitro assay-based approaches. Incubation of in vitro-translated atxn3 with apoptotic osteosarcoma cell extracts or with purified caspases led to the formation of fragments with 14 and $18 \mathrm{kDa}$, resulting from nonexpanded and expanded atxn3, respectively [25]. In in vitro proteolysis assays of purified recombinant non-expanded human atxn3 using $\mathrm{N} 2 \mathrm{a}$ cells postnuclear supernatant preparations, five main atxn3 fragments have been identified: a $29 \mathrm{kDa}$ product derived from the endogenous mouse protein, and four other fragments derived from the human non-expanded protein, with about 16, 20, 24 and $34 \mathrm{kDa}$ [68]. Another report observed that incubating atxn3expressing lysates with calpains in vitro gave rise to a fragment of $\sim 30 \mathrm{kDa}$. This fragment was predicted to correspond to an $\mathrm{N}$ terminal portion of the protein, and in fact its molecular size was independent from the polyQ length of the parental atxn3. The fragment derived from both expanded and non-expanded overexpressed human atxn3, in human embryonic kidney (HEK) 293T cells, as well as from the endogenous mouse protein and expanded human atxn3, in transgenic mouse brain tissue [76].

Atx3n fragments have also been detected in cell lines, in the absence of exogenous protease incubation. One study with Drosophila SL2 cells expressing expanded human atxn3 yielded several fragments, including a major $\sim 50 \mathrm{kDa}$ species [70]. In transfected N2a cells, expanded atxn3 was shown to generate polyQ-containing species ranging from 32 to $62 \mathrm{kDa}$ (the size of the full-length form) [75]. Another study probing transfected COS-7 cell extracts men- 
tioned a great variety of fragments: non-expanded murine atxn3 was shown to generate four C-terminal fragments (of about 18, 21, 28 and $42 \mathrm{kDa}$ ) and two N-terminal fragments (with 37 and 42 $\mathrm{kDa}$ ), while the expanded human protein generated only two Cterminal fragments (the recurrent $37 \mathrm{kDa}$ fragment and another with about $50 \mathrm{kDa}$, that could be equivalent to the $42 \mathrm{kDa}$ product of the murine protein) [67]. Several polyQ-containing species, of different sizes $(25$ to $32 \mathrm{kDa}$ ), have been mentioned to derive from human expanded atxn3 expressed in HEK 293T cells [68]. Caspase activation in these cells led to the formation of two endogenous atxn3derived fragments, with $\sim 28$ and $30 \mathrm{kDa}$ [68].

Recent experiments using brain homogenates from mice locally transduced with human atxn3 by lentiviral injection described atxn3 species of about $26 \mathrm{kDa}$ that, in light of their reactivity with different antibodies, correspond to several different fragments [71, 72]. Both non-expanded and expanded atxn 3 generate $26 \mathrm{kDa}$ fragments that contain the N-terminus of the protein, but a fragment of similar size - and necessarily distinct - is also detected with the 1C2 antibody [72]. In the case of non-expanded atxn3 this polyQ-containing species could correspond to the recurrent $\mathrm{C}$-terminal product recurrently described; for expanded atxn3, a $26 \mathrm{kDa}$ fragment containing the polyQ tract could be explained by a cleavage event at another, downstream, position.

Studies performed in neuronal cultures generated from humanderived induced pluripotent stem cells (iPSCs) detected a clear 34 $\mathrm{kDa}$ atxn3 fragment which was curiously present (and had the same size) in both SCA3/MJD patients and controls, in agreement with its predicted $\mathrm{N}$-terminal nature [77]. In the same study, other fragments of diverse molecular sizes $(25-45 \mathrm{kDa})$ were also shown to be generated, but were only significantly detected in patient-derived neurons.

The diversity of fragments hereby enunciated may be overstated, and more than one of the species described may result from common proteolytic processes that nonetheless yield apparently different products in the corresponding studies. Some molecular weight differences of the detected fragments likely result from the fact that experiments employ different forms of atxn3; the studies mentioned have analyzed atxn3 from different animal species, with variable polyQ sequence lengths and, in some cases, carrying peptidic tags. Variation may logically also result from differences in sample preparation conditions, probing methods and molecular weight estimations, and it is also not surprising that atxn 3 may be differently cleaved in such considerably dissimilar experimental models.

It could be argued that some of the lower molecular weight atxn3-derived species mentioned in the available studies correspond to uncharacterized protein products of the numerous transcripts of the ATXN3 gene that have been identified to date [78, 79]. However, among the above studies that analyzed atxn3-encoding transcripts, none was able to detect more than one PCR product in reverse transcriptase-PCR experiments [69,74]. Again, the fact that blocking protease activity (described below) limits the detection of smaller atxn3 products agrees with the idea that the species addressed in these studies correspond to stable cleavage products.

The reported heterogeneity of the atxn 3 fragments detected so far illustrates the fact that atxn 3 may be proteolytically processed in different ways and that, apart from the recurrent C-terminal polyQcontaining fragment, stable cleavage products may also result from other regions of the protein. Importantly, available evidence clearly indicates that proteolytic processing of atxn3 is not exclusive of the pathogenically expanded form of the protein, but targets also nonexpanded atxn3.

\subsection{Atxn3-Targeting Proteases and Cleavage Sites}

Investigation into the enzymes mediating atxn3 cleavage largely supports the involvement of caspases $[67,70,74]$ and cal- pains $[68,71,72,76]$ in the process. Atxn3 displays several putative cleavage sites for both families of enzymes [25, 67, 70, 74], and some of them have been experimentally suggested to be actual biologic targets of their activity (Fig. 1).

\subsubsection{Caspases}

Caspases are cytosolic cysteine proteases that have a welldocumented role in apoptotic cell death, participating in signal transduction pathways and in the associated dismantling of proteins [80]. After the initial studies demonstrating that apoptotic cell extracts and purified caspases were able to cleave in vitro-translated atxn3 [25], endogenous atxn3 was shown to be proteolyzed in different cell cultures upon stimuli with staurosporine [74], a compound that induces apoptosis and consequently initiates the accompanying cascade of caspase activation [80]. While in some cells the staurosporine stimulus resulted in the complete proteolysis of atxn3 or only in a modest reduction in the levels of the full-length protein, in COS-7 cells this paradigm led to the robust loss of full-length atxn3 and to the consistent formation of a fragment - the main Cterminal product mentioned above, with $28 \mathrm{kDa}$ since it derives from endogenous African green monkey atxn3 [74]. Intriguingly, while caspase inhibition did not prevent cleavage of in vitrotranslated atxn3 [25], a broad caspase inhibition by carbobenzoxyvalyl-analyl-aspastyl-[O-methyl]-fluoromethylketone (zVAD-fmk) limited the appearance of the fragment in COS-7 cells [74]. Furthermore, while caspase- 1 and -3 (and not caspase- 7 or -8 ) were able (albeit modestly) to cleave atxn3 in vitro [25], experiments with inhibitors of specific caspases suggested that, in COS-7 cells undergoing staurosporine-induced apoptosis, caspase-1 was the primary caspase involved in atxn3 processing [74]. Interestingly, human atxn 3 overexpressed in the same cells was also cleaved in a caspase-dependent manner, but even in the absence of staurosporine stimulation [74]. In HEK 293 cells, exogenous caspase stimulation by cytochrome C and ATP treatment also led to the proteolysis of endogenous atxn3 [68].

Caspases cleave proteins in the vicinity of aspartate residues, and nine putative caspase cleavage sites have been identified in the amino acid sequence of atxn3, with at least eight being conserved in mammalian species [74]. Supporting the involvement of caspases in atxn3 proteolysis, cleavage of exogenous human atxn3 in COS-7 cells was abrogated upon mutation of those nine putative caspase cleavage sites [74]. Because caspases may display some cleavage site redundancy, mutation of a few aspartate residues is seldom sufficient to fully block proteolysis, thereby turning the identification of an individual cleavage site as the main physiologic target difficult $[70,74]$. It was however demonstrated that simultaneous mutation of aspartate residues 241, 244 and 248, a cluster contained in the ubiquitin-interacting motifs (UIMs) 1 and 2 of atxn3 and localized in the $\mathrm{N}$-terminal vicinity of the polyQ sequence limited atxn3 proteolysis in COS-7 cells (in contrast with the concurrent substitution of residues 145, 171, 208, 217, 225 and 228) [74].

Through amino acid sequencing and/or mass spectrometric analysis of the fragments produced in another study using the same cell line, Pozzi and collaborators mapped the cleavage sites of murine (non-expanded) atxn3 to D168, E214, D241, R319 and S329, all of which were mentioned to be near to or contained in possible caspase cleavage sites [67]. The same study determined that the 37 $\mathrm{KDa}$ fragments produced by human expanded atxn 3 started at D168.

Broad caspase inhibition by zVAD-fmk decreased the formation of the $\sim 37 \mathrm{kDa}$ polyQ-containing fragment in Drosophila SL2 cells expressing human atxn3 [70]. In these cells, mutation of six potential caspase-target aspartate residues $(171,208,217,223,225$ and 228 ) extensively eliminated the $\sim 37 \mathrm{kDa}$ fragment. In the transgenic Drosophila model brain, mutation of those residues also decreased the formation of the major $\sim 37 \mathrm{kDa}$ fragments (a dou- 


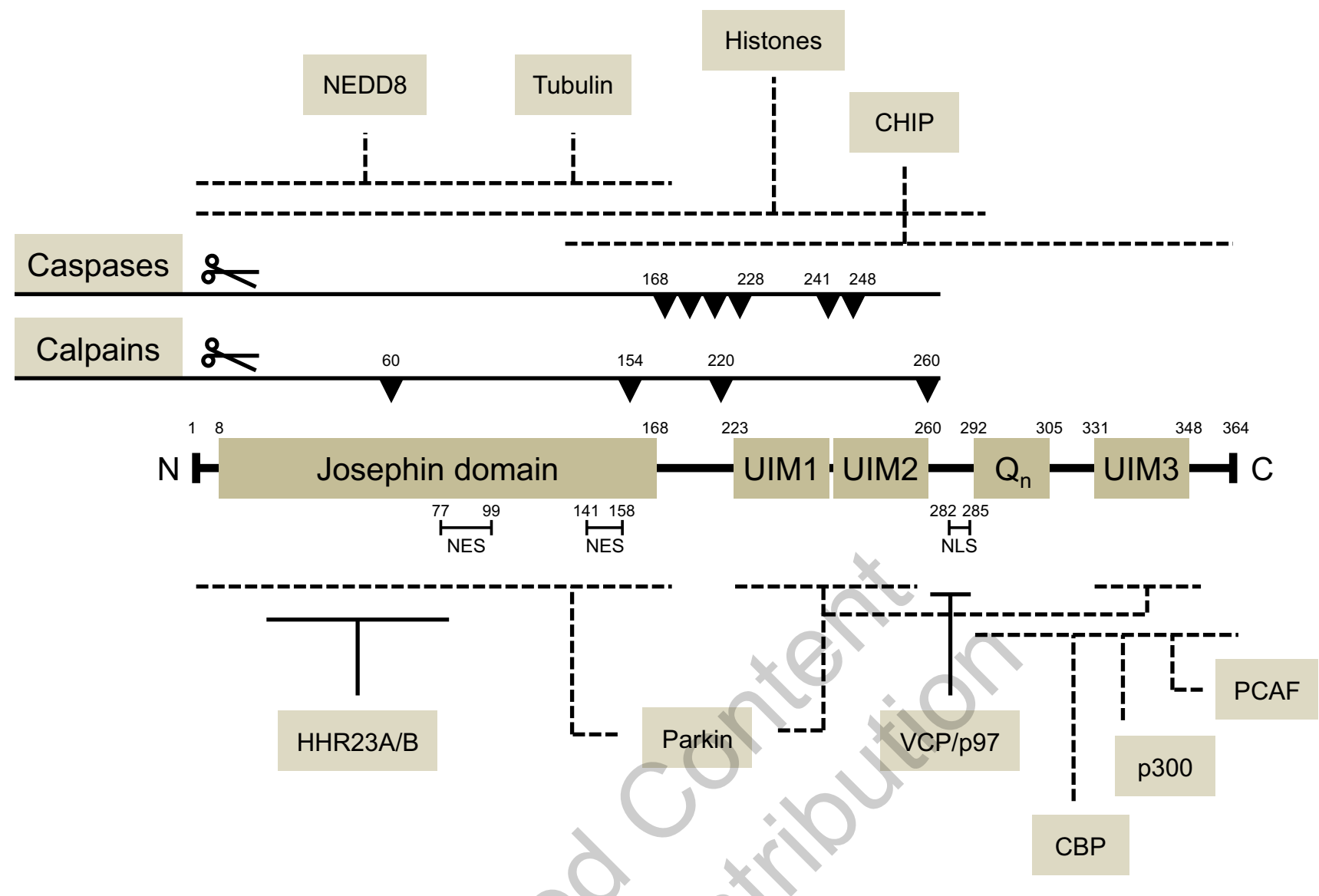

Fig. (1). Ataxin-3 putative cleavage sites. Mapping of atxn3 cleavage sites is still inconclusive, but some putative regions have been identified so far. For caspases, cleavage apparently occurs near the UIMs, assumedly between amino acids 168-228 [67, 69, 70] and/or 241-248 [74]. For calpains, the cleavage sites suggested are mapped around residues 60,154,220 and $260[68,71,76]$. Atxn3 subcellular targeting sequences and direct molecular interactors are also represented; continuous lines indicate interactions known to be mediated by limited regions of atxn3 and interrupted lines denote interactions which have been mapped with lesser regional detail to particular protein domains. Domain annotation is based on the UniProt reference sequence of human atx3 (code P54252) with 3 UIMs and a polyQ sequence with 14 repeats [151].

blet) observed in the model, supporting an in vivo role for these enzymes in atxn3 cleavage [70].

\subsubsection{Calpains}

Calpains are cysteine proteases that are activated by the rise of intracellular calcium concentration [81]. The involvement of calpains in atxn 3 proteolysis was first hinted during in vitro assays, in which cleavage of the recombinant protein upon incubation with N2a cell lysates was potentiated by calcium stimuli [68]. Calciumdependent cleavage was also observed in lysates from HEK 293 cells and transfected N2a cells and in every model it was repressed by the calpain inhibitor N-acetyl-L-leucyl-L-leucyl-leucyl-Lnorleucinal (ALLN). In living N2a cells, the calcium ionophore ionomycin increased murine and exogenous atxn3 proteolysis, while the calpain inhibitor calpeptin limited fragmentation. Furthermore, coexpression in HEK 293T cells of human expanded atxn3 and calpastatin, an endogenous calpain inhibitor, limited formation of the polyQ-containing fragments that arise even in the absence of exogenous calcium stimulus [68].

Later evidence supports an in vivo role for calpains. Timeresolved Förster resonance energy transfer (TR-FRET) experiments suggested that knock-down of caspastatin increased atxn3 fragmentation in transgenic mice overexpressing expanded human atxn3 and that this cleavage event is potentiated by calcium stimulation [76]. Similarly, in the brain of lentivirally-injected mice, production of human atxn3-derived fragments was reduced upon calpastatin coexpression [71] or pharmacological calpain inhibition by BDA410 [72]. Moreover, lentiviral-mediated expression of mutant atxn3 induced a local depletion in the brain of calpastatin-overexpressing transgenic mice [71]. The fragments produced in human iPSCsderived neurons, generated upon glutamate stimulus, where not detected under incubation with ALLN or calpeptin [77].

Calpain-1 and calpain-2 are the two best characterized members of the calpain family of proteases and are abundant in the brain. In vitro incubation of transfected HEK $293 \mathrm{~T}$ cell extracts or mouse brain homogenates with recombinant calpains informed that, although both enzymes are able to process atxn3 (human and murine in each model, respectively), calpain-2 acts with more efficiency [76]. Importantly, while calpain-1 respondes to calcium concentrations in the micromolar range, calpain-2 responds to concentration in the millimolar range [76].

Microsequencing of the main fragments resulting from in vitro proteolysis of atxn3 with recombinant calpain-2 indicated that cleavage occurred next to amino acids 60,200 and 260 [68]. The calpain activity-dependent fragments detected in the lentiviral mouse model were predicted to result from proteolysis at amino acids $60-61,154,220$ and 259-260, taking into account antibody immunoreactivity and electrophoretic movement [71, 72]. The results of the TR-FRET experiments were compatible with cleavage at a region between the $1 \mathrm{H} 9$ antibody epitope (221-224) and the polyQ region; possibly amino acid position 260 [76]. 


\subsubsection{Other Proteases}

The relative importance of caspases and calpains on atxn3 cleavage is, to a certain extent, still a matter of debate. Some of the studies supporting the role of caspases failed to detect an effect of calpain inhibition on fragment formation [70,74], and the same can be said for other reports addressing calpains and the inhibition of caspases $[68,77]$. This could be associated with the fact that some of these reports employ paradigms (apoptosis induction, glutamate or calcium stimulation) that may potentiate the activity of one enzyme group over the other, but inhibitor-sensitive proteolysis has also been detected in the absence of any stimuli [68, 71, 72, 74], supporting the biologic relevance of both caspases and calpains. What is more, though in many cases fragment detection has focused mainly on exogenously-expressed human atxn3, giving rise to the possibility that the overexpression of atxn 3 directs its cleavage, endogenous atxn 3 proteolysis has been shown to be sensitive to caspase $[68,82]$ and calpain $[68,77]$ inhibition as well.

It is still unclear whether the generation of a specific fragment, with a typical molecular size and a repeated topology, may be mediated only by one designated enzyme or, alternatively, if more than one protease may yield similar fragments or even act in a concerted way. As a prominent example, the enzyme responsible for the formation of the recurring 34-37 $\mathrm{kDa} \mathrm{C}$-terminal fragment remains uncertain. Goti and coworkers predicted that the $37 \mathrm{kDa}$ fragment detected in transgenic mice would result from cleavage at a position $\mathrm{N}$-terminal of residue 221 , based on the fact that the fragment reacted with the 1H9 antibody that recognizes amino acids 221-224, but not with other antibodies directed at anterior epitopes [69]. Considering that elimination of residues 190-220 does not abrogate formation of an equivalent fragment, the cleavage site was later narrowed down to amino acid 190 [73]. Two caspase sites were considered as putative targets: the ones including aspartates 145 and 171. However, the size of truncated forms of atxn3 lacking amino acids $1-145$ or $1-171$ did not match the $\sim 37 \mathrm{kDa}$ fragments detected in the transgenic mice [69], arguing against caspase involvement. Latter, however, Pozzi and collaborators determined that human expanded atxn3 gives rise to a $37 \mathrm{kDa}$ fragment starting at aspartate 168 , consistent with caspase cleavage nearby amino acid 171 [67]. It should be noted that the reported molecular size of the full-length expanded atxn3 were dissimilar: $58-64 \mathrm{kDa}$ and $54 \mathrm{kDa}$, respectively. Regardless of these considerations, there are examples of both caspase $[70,74]$ and calpain $[68,71,72]$ inhibitors decreasing the formation of $34-37 \mathrm{kDa}$ fragments, suggesting the involvement of both families of enzymes. It is also possible that, despite the similarities in fragment topology and molecular size existing between studies, the polyQ-containing species detected correspond to different products, resulting from different cleavage events. In fact, studies focusing on calpain-mediated cleavage describe the fragments as migrating at $34 \mathrm{kDa}[68,71,72,77]$, rather than $\sim 37 \mathrm{kDa}$. It could be the case that both caspases and calpains may give rise to to different polyQ-containing atxn3 fragments of similar size: caspases cutting at around amino acids 168-171 [67], and calpains cutting at a C-terminal position such at amino acid 200 or 220 $[71,72]$.

This example may guide to the conciliatory idea that, in a physiologic setting, atxn3 may be proteolyzed by more than one enzyme, each perhaps acting in a concerted and/or sequential manner [83]. This idea of a multistep proteolysis also helps explain the observation of diverse fragments that are differently affected by particular protease inhibitors [70]. Inter-study variations in fragment size and number may result from differences in the experimental conditions - such as those pertaining to the analysis of different atxn3 forms (endogenous protein versus overexpressed atxn3; differences in polyQ repeat length; analysis of different variants) or the experimental models used to mediate cleavage (cellbased systems versus in vivo models; different experimental conditions; use or absence of chemical stimulation) - that push the sys- tem in a particular direction. Under the staurosporine-induced apoptotic paradigm, for example, atxn 3 cleavage varies drastically between different cell cultures [74].

Apart from caspases and calpains, the involvement of other proteases has been seldom supported. The sequencing study by Pozzi and collaborators described a cleavage event occurring between Y27 and P28 of murine and human atxn3 that led to the formation of the 42 and $50 \mathrm{kDa}$ fragments observed (for each species, respectively) [67]. It was predicted to be mediated by a chymotrypsin-like protease, but there is still no experimental evidence supporting such event. Cysteine/serine protease inhibitor leupeptin reduced atxn3 calcium-stimulated cleavage [68] but not cleavage stimulated by glutamate [77]. The serine protease inhibitor aprotinin, as well as the aspartyl protease inhibitor pepstatin, were unable to reduce cleavage under either stimulus $[68,77]$.

Studies with proteasome inhibitors have overall failed to observe a significant contribution to fragment formation [70, 82]; only in the case of calcium-elicited fragmentation was the inhibitor MG132 shown to reduce proteolysis, but it is possible that this effect was due to its simultaneous action as a calpain inhibitor [75]. On the other hand, it is important to consider that ALLN, the calpain inhibitor used in some studies [75-77] is also known to inhibit the proteasome, giving rise to the possibility that some ALLN-sensitive cleavage is due to the action of the proteasome. Matters become even more blurred considering that both ALLN and MG-132 inhibitors may induce apoptosis $[84,85]$.

Finally, an in vitro study curiously reported evidence that purified atxn 3 is subjected to slow autolytic fragmentation, catalyzed by the $\mathrm{C} 14$ of the active site. It was determined by mass spectrometry of the diverse resulting fragments that atxn3 autoproteolysis displays no defined specificity. The JD is nevertheless preserved in the process, since the cleavage sites are clustered at the $\mathrm{C}$-terminal region of the protein (C-terminally of L191)[86].

\subsection{Atxn3 Fragment-Derived Toxicity}

The scientific interest on atxn3 proteolytic cleavage is fundamentally related to its potential relevance in the pathogenic mechanisms leading to neurodegeneration in SCA3/MJD. Indications of the increased toxicity of atxn3-derived fragments compared to the full-length protein derive mainly from a) cell and animal models expressing truncated forms of atxn3, b) reports associating cleavage of expanded atxn3 with disease or disease-related outcomes, c) studies altering atxn3 proteolytic cleavage through chemical stimulation or protease inhibition and d) reports expressing cleavageresistant mutants of atxn3.

The first clues arose from studies with cell cultures transfected with truncated atxn3. COS-7 cells expressing a truncated form of expanded atxn 3 that only included the $\mathrm{C}$-terminal region of the protein showed apoptotic features that were absent from cells expressing the full-length protein or the equivalent non-expanded fragments [87]. Additionally, while these atxn3 forms were distributed homogenously in the cytoplasm, the expanded C-terminal fragment tended to amass in a punctuate pattern [87]. Comparable results supporting the increased cytotoxicity and tendency to aggregate of the $\mathrm{C}$-terminal expanded atxn3 truncations were later obtained in HEK 293T [61, 88], BHK-1 [89] and N2a cells [69, $75,90]$.

Studies with the first SCA3/MJD animal models corroborated these observations. Of the several transgenic mice generated by Ikeda and collaborators [87], animals expressing a polyQcontaining C-terminal fragment of expanded atxn3 under the control of a Purkinje cell promoter exhibited a motor postural phenotype that was absent from animals expressing the full-length expanded protein, or an equivalent fragment with non-expanded glutamines. Similarly, in Drosophila, expression of a C-terminal fragment in eye cells led to severe degeneration, while expression of the 
full-length protein produced a mild phenotype [91, 92]. More recently, severe neurodegeneration has also been described in Torashima and collaborators' SCA3/MJD mouse model, which expresses a C-terminal fragment of atxn3 [93-97].

This early evidence suggested that expanded atxn3 toxicity is caused by C-terminal fragments of atxn3 containing the expanded polyQ sequence, rather than by the full-length protein [69]. While results obtained with later cell and animal models demonstrate that expression of the full-length protein triggers degeneration and SCA3/MJD-related phenotypes [56, 83], the C-terminal fragments of atxn 3 are still considered to be more toxic than the full-length protein $[71,73]$. Atxn3 proteolytic cleavage is thus envisioned as being crucial to SCA3/MJD pathogenesis, or at least to contribute to the disease mechanisms.

A correlative study with animal models and patients supports a role for atxn3 cleavage in SCA3/MJD. In the transgenic mouse model generated by Goti and collaborators, the polyQ-containing $36 \mathrm{kDa}$ fragment was interestingly found throughout several brain regions and in the spinal cord and was particularly abundant in the cerebellum, but was reported to be absent from peripheral tissues, contrary to the full-length protein [69]. Coincidently, the nervous tissue is admitted to be a specific target for degeneration in SCA3. Additionally, among the mice expressing expanded atxn3, the polyQ fragment was enriched in animals presenting a SCA3-related phenotype and was found to be scarcer in transgenic animals with normal behavior. [69]. A $\sim 35 \mathrm{kDa}$ fragment was also identified in the cerebellum, substantia nigra and cortex of SCA3 patients and was found to be more abundant in the first two regions [69], which are more severely implicated in disease neuropathology [9]. The fragment was not detected in control patients' cerebellum [69]. More recently, some of the aggregate-prone fragments $(25-45 \mathrm{kDa})$ observed in human iPSCs-derived neurons upon glutamate stimulation were described to be exclusively detected in SCA3/MJD patient-derived cells [77].

Studies addressing the consequences of altering the activity of caspases and calpains in SCA3/MJD SCA3 models oftentimes support the idea that proteolysis of atxn3 contributes to the toxicityrelated features of those systems. In transfected COS-7 cells, expanded atxn3 aggregation is increased upon staurosporine stimulation and reduced with zVAD-fmk treatment [74]. In transgenic flies, the mutation of six putative caspase-target aspartate residues that was shown to decrease fragment formation was demonstrated to mitigate atxn3 aggregation and neural loss in the eye (though not inclusion formation) [70]. Calpeptin treatment and calpastatin coexpression reduced the formation of SDS-resistant aggregates of expanded atxn3 in transfected N2a and HEK $293 \mathrm{~T}$ cells, respectively [68].

In a lentiviral SCA3/MJD mouse model expressing expanded atxn3 in the striatum, calpain inhibition by calpastatin coexpression reduced inclusion formation and neurodegeneration [71]. The calpain inhibitor BDA-410 produced similar effects in this model and was further demonstrated to ameliorate motor symptoms occurring in animals expressing the protein in the cerebellum [72]. Concordantly, knocking-down calpastatin in a transgenic SCA3/MJD mouse model had opposite effects, aggravating the behavioral phenotype, worsening the neurodegeneration profile and increasing inclusion number [76]. In neuronal cultures derived from patients' iPSCs, glutamate and calpain-dependent atxn3 fragmentation was correlated with atxn3 aggregation, in the sense that a robust portion of the species forming SDS-insoluble aggregates were fragments that were also largely absent from soluble atxn3 fractions [77]. Importantly, calpain inhibition by ALLN or calpeptin reduced both aggregate formation and aggregation induced by glutamate stimulation in the patient-derived model.

\subsection{Mechanisms of atxn3 Fragment-Derived Toxicity}

Since it was first observed, the link existing between aggravation of degenerative phenotypes and atxn 3 truncation has suggested that proteolytic cleavage of expanded atxn 3 constitutes an important step in the pathogenesis mechanisms of SCA3/MJD [98]. It is critical to understand this connection, since comprehending what are the mechanisms that turn atxn 3 more toxic upon fragmentation could yield precious clues into the molecular events taking place during the development of the disease and possibly inform on promising targets for therapeutic intervention.

\subsubsection{Atxn3 Proteolysis and Aggregation}

Aggregation is envisioned as being not only a hallmark of polyQ diseases, but also as a source of cell toxicity ultimately at the base of these disorders [15, 19]. While the macromolecular inclusions that have been described in the nervous system of patients of SCA3/MJD and other polyQ diseases $[10,61]$ are currently admitted to actually be the end-stage result of protective mechanisms mobilized against actual sources of toxicity [19], other species formed as the result of atxn3 self-assembly are believed to be actively deleterious [20]. It is admitted that simpler intermediaries of the aggregation pathways - in particular soluble oligomers of amyloid-like nature - perturb cell functions in a number of ways, including by sequestration of other proteins or by destabilization of lipid membranes [15, 99-103].

It is possible that fragmentation increases atxn 3 toxicity by triggering, facilitating or increasing aggregation. As detailed above, studies focusing on atxn3 proteolytic cleavage frequently report changes in aggregation propensity: cleavage-inducing paradigms have been shown to drive atxn3 aggregation and atxn 3 fragments have been demonstrated to have an increased tendency to aggregate compared to the full-length protein, in diverse cell $[61,68,75,77$, 82, 87-90] and animal models [70-72, 76].

Several of the studies comparing the aggregation propensity of full-length atxn3 versus atxn3 truncations failed to detect any accumulation of the full-length expanded protein, in vitro [75] and in cells $[61,98]$. Even when this is not the case, truncated forms of atxn3 containing the $\mathrm{C}$-terminal part of the protein have been repeatedly observed to be more prone to aggregate $[75,89,90]$. If atxn3 fragmentation was essential for aggregation, it would be expectable that only fragmented species would make up the aggregates, even in models expressing the full-length protein. Interestingly, however, authors have also described that, besides fragments, full-length atxn 3 is also detected in aggregate fractions $[75,77]$.

The presence of full-length atxn3 in aggregates may be taken to mean that fragmentation is not essential for aggregation, but it is nevertheless possible that this event may precipitate aggregation. During the course of a particular set of in vitro experiments, fulllength expanded atxn3 was unable to form significant aggregates, contrary to C-terminal truncated forms (starting at amino acid 257). Curiously, incubation of full-length atxn 3 and the C-terminal fragment led to aggregation of the full-length protein, in a process that occurred even with the non-expanded protein, but that was intensified with increased numbers of glutamines [75]. Parallel results have been obtained in coexpression experiments made in N2a [75] and HEK 293T cells [61, 88]. Evaluation of aggregation propensity in these systems is usually based on filter retardation procedures, Western blot detection of aggregating species, and immunocytochemical observation of protein deposits. Considering these results and the robust aggregation of polyQ-containing truncated atxn 3 in vitro and in cells, it has been suggested that the full-length protein is unable to initiate aggregation, but is nonetheless apt to coaggregate. Protein cleavage with loss of the N-terminal region, admitted to protect the protein against aggregation, may be responsible for triggering self-assembly [75]. Supporting this idea, 
artificially provoking cleavage of expanded atxn3 at residue 257 leads to aggregation, in cells [75]. The fact that even non-expanded atxn3 is also susceptible to coaggregation $[75,88]$ raises the possibility that, in the case of heterozygous SCA3/MJD patients, proteolysis of the expanded allele product and subsequent aggregate seeding will hamper the non-expanded protein by recruiting it into the forming aggregates.

\subsubsection{Atxn3 Proteolysis and Biologic Function Perturbation}

Protein self-assembly and aggregation may be considered one facet of a broader putative mechanism of toxicity resulting from polyQ expansion: the establishment of aberrant intermolecular interactions [15]. Recruitment of important cellular proteins and the consequent perturbation of cell systems that are crucial for cell survival and functioning may be ultimately nefarious to the cells. Proteolytic cleavage of atxn3 may alter the molecular interactions established by the protein by corrupting particular interaction surfaces or by excluding particular atxn 3 domains from a designated interaction, due to physical separation.

Atxn3 interacts with valosin-containing protein (VCP)/p97 through a linker region (amino acids 277-291) existing between the second UIM and the polyQ sequence $[104,105]$. It is possible that atxn3 fragmentation alters their interaction, considering that at least one calpain cleavage site has been predicted to be present in the vicinity of the interacting region $[68-71,76]$. VCP/p97 has been shown to mitigate toxicity in the eye of Drosophila expressing expanded atxn3, but such an effect was absent from flies expressing C-terminal truncated atxn3 that lacked the complete VCP/p97 binding motif described $[91,104]$. An altered interaction between atxn3 and $\mathrm{VCP} / \mathrm{p} 97$ may perturb their regular functions; $\mathrm{VCP} / \mathrm{p} 97$ is known to play diverse cellular roles, being particularly implicated in protein quality control systems involving the ubiquitin proteinproteasome pathway, such as the endoplasmic reticulum-associated degradation pathway $[105,106]$. Interaction between $\mathrm{VCP} / \mathrm{p} 97$ and atxn3 is believed to be related to their concerted function in these systems $[107,108]$. Curiously, atxn3 interaction with $\mathrm{VCP} / \mathrm{p} 97$ in a transfected cell line was increased by atxn3 polyQ expansion, and the two proteins colocalize in nuclear inclusions of SCA3/MJD patients [104]. The involvement of atxn3 cleavage in these changes remains to be determined, but it is possible that fragment-driven aggregation potentiates recruitment of $\mathrm{VCP} / \mathrm{p} 97$.

Atxn3 has been reported to interact with other proteins implicated in protein homeostasis maintenance. The protein interacts with the human homologs of the yeast DNA repair protein $\operatorname{Rad} 23 \mathrm{~A}$ and B (HHR23A/B) through the JD [105], as well as several E3 ubiquitin ligases: it binds C-terminus of $70 \mathrm{kDa}$ heat shock proteininteracting protein (CHIP) through a region $\mathrm{C}$-terminal of amino acid 133 [109] and parkin through both the JD and the UIMs [110, 111]. Other atx 3 interactors include cytoskeleton-associated proteins such as tubulin, that interacts with the JD [108, 112]; proteins involved in transcription regulation, including cyclic AMPresponsive element-binding protein (CREB)-binding protein (CBP), p300 and p300/CBP-associated factor (PCAF), that bind a polyQcontaining $\mathrm{C}$-terminal region of atx 3 , and histones, that interact with atx3 N-terminally of the polyQ region [113, 114]; and the neural precursor cell expressed developmentally downregulated gene 8 (NEDD8), a small ubiquitin-like protein that binds to the JD [115] . As these molecular partners interact specifically with particular regions throughout atxn3 sequence [99], it is reasonable to admit that cleavage may influence at least a subset of the interactions (Fig. 1). Binding blockade or binding without access to the whole protein and its domains may interfere with the molecular partners and their cellular activities, eliciting toxicity.

Fragmentation of atxn3 may also disturb its activity as a deubiquitinase. Ubiquitinated substrates are believed to interact with atxn3 in a manner dependent on both the UIMs and two ubiquitinbinding regions existing at the surface of the JD [116, 117]. Cleav- age of atxn3 may not only compromise these interacting surfaces, but also unhinge the dynamics of substrate processing, since atxn3mediated deubiquitination is believed to require the cooperative action between the UIMs, that recruit polyubiquitin chains, and the JD ubiquitin-binding sites, that orient the isopeptide bonds for cleavage at the JD active site $[117,118]$. Atxn3 fragmentation may separate these regions, hindering proper substrate processing. In vitro, the cleavage preferences of full-length atxn3 (in terms of ubiquitin chain linkage type) are abolished when the C-terminal region of the protein is eliminated, in a manner that is reminiscent of UIM mutation [118, 119]. Again, disturbance of atxn3-mediated deubiquitination of particular substrates and the consequent alteration in their turnover or activity may also constitute bases for cell toxicity. What is more, the JD domain of atxn3 has been proposed to not only thwart aggregation, but to actively protect against polyQ toxicity by means of its enzymatic activity (possibly involved in protein degradation pathways) [91]. Atxn3 cleavage may thus trigger toxicity by separating the JD from the polyQ-containing Cterminal region [70].

\subsubsection{Atxn3 Proteolysis and Nuclear Accumulation}

Nuclear localization is commonly regarded as an important factor in expanded atxn3 toxicity, with reports suggesting that the pathogenic expansion leads to accumulation of the protein in the nucleus and that this accumulation is deleterious to the cells $[56,59$, $63,64]$. The nuclear environment may potentiate aggregation and consequent sequestration of other proteins - seeing as targeting non-expanded atxn3 to the nucleus leads to aggregate formation $[59,64]-$ or it may protect the protein from degradation [90]. Additionally, expansion-induced changes of the functional role of atxn3 in the nucleus, in particular as a transcription regulator, may also be deleterious to the cell $[113,114,120-125]$. Cleavage may enhance atxn3 toxicity by increasing the levels of the protein in the nucleus, possibly as a consequence of the fragments produced being more prone to be shuttled to this compartment and/ or because they are more stably kept there.

Though initial studies using cell lines expressing polyQcontaining atxn 3 fragments mentioned that accumulations could be found in the cytoplasm and in the perinuclear region $[61,88,89$, 98], some did not fail to detect deposits that matched the nuclear localization commonly attributed to the inclusions detected in SCA3/MJD patients $[61,89]$. In agreement with an increased nuclear accumulation of C-terminal atxn3 truncations in comparison to the full-length expanded protein, the nuclear deposits were found to be less frequent [89] or completely absent from cells expressing the full-length protein [61]. Adding to these reports analyzing the subcellular distribution of atxn3 truncations, in transfected COS-7 cells a $50 \mathrm{kDa}$ fragment of human atxn 3 containing the $\mathrm{C}$-terminus of the protein was determined to be more nuclear than the corresponding $42 \mathrm{kDa}$ species resulting from non-expanded murine atxn3 [67]. Importantly, the $\sim 36 \mathrm{kDa}$ atxn3 fragment detected in symptomatic transgenic mice and SCA3/MJD patient's brain tissue was enriched in nuclear fractions, that also presented increased levels of aggregates [69]. Though in transgenic mice the full-length protein was also more nuclear, overall these observations support the hypothesis that at least some atxn3 fragments display a tendency to accumulate in the nucleus.

Atxn3 has been found to include a functional nuclear localization signal (NLS) between the second UIM and the polyQ stretch (amino acids 282-285, contained in the region described to mediate the interaction with $\mathrm{VCP} / \mathrm{p} 97)[59,104,126]$, as well as two potentially functional nuclear export signal (NES) in the JD (residues 7799 and 141-158; Fig. 1) [59, 127]. Proteolytic cleavage of atxn3 that results in the separation of protein domains bearing different localization signals may unbalance subcellular shuttling. For example, cleavage between the JD and the polyQ region may produce $\mathrm{C}$ terminal fragments that comprise the identified NLS but lack the 
NES, leading to the transport of polyQ-containing species to the nucleus, which will no longer be able to be shuttled back to the cytoplasm due to the absence of the NES signals [128]. While the identified NLS has been reported to be unessential for nuclear transport [67], as C-terminal fragments that do not contain it may also localize in the nucleus [90], it is also conceivable that atxn3 cleavage may disrupt more complex localization motives that include regions in distant parts of the protein [59].

Observation of increased nuclear aggregation of atxn3-derived fragments may be a consequence of increased nuclear translocation of the aggregate-prone species, the greater tendency to aggregate that they exhibit or a combination of the two. Interestingly, artificially targeting non-expanded C-terminal fragments of atxn3 that would otherwise distribute diffusely in cell led to the formation of inclusions [61, 88]. This observation may be interpreted as a testimony of the effect of the nuclear environment in driving aggregation.

Experimental evidence also suggests that nuclear accumulation of atxn3 fragments may be due to their inefficient degradation inside this cell compartment. Contrary to C-terminal fragments targeted to the cytoplasm, equivalent fragments targeted to the nucleus maintained their steady-states and tendency to aggregate upon artificial stimulation of a protein degradation-inducing cellular stress response [90]. Results suggest that in the nucleus the fragments are less susceptible to proteasomal degradation [90], and it is conceivable that the protein is also less susceptible to autophagy where inside this cell compartment [129].

\subsubsection{Atxn3 polyQ Expansion and Susceptibility to Cleavage}

The "toxic fragment hypothesis" postulates that cleavage of polyQ-containing proteins and the subsequent production of deleterious fragments initiate - or at least accelerate - the pathogenic cascade leading to polyQ disease-related cell degeneration $[25,68$, 74]. In order to assess the importance of atxn 3 proteolysis in SCA3/MJD, it is important to question what is the full extent of the link existing between three factors: (i) the expansion of the polyQ tracts beyond the disease-associated threshold (ii) the susceptibility of the protein to cleavage and (iii) the toxicity of fragments formed by proteolytic cleavage. Conceptually, polyQ expansion of atxn3, cleavage and fragment toxicity may be causatively related through one of the following rationales: a) atxn3 is subjected to proteolysis irrespectively of polyQ sequence size, but only fragments resulting from the expanded protein are toxic (or are more toxic); b) atxn3 fragments are toxic irrespectively of their size, but only polyQexpanded atxn3 gives rise to stable fragments or is more easily proteolyzed. Overall, available experimental evidence supports the first proposition and perhaps suggests a combination of the two.

Detection of fragments only in symptomatic transgenic animals or in SCA3/MJD patients but not in controls [69] would suggest that fragmentation is exclusive of disease states. However, nonexpanded atxn3, both when heterologously expressed [67, 68, 70$72,82]$ or when present as an endogenous protein [68, 74, 76, 77], has been found to produce stable fragments in several systems, indicating that proteolysis does not target pathogenic atxn3 exclusively. Importantly, as mentioned before, in many of those systems protease activity was artificially stimulated, possibly exacerbating proteolysis. Even in the studies when this was not the case, atxn3 was being overexpressed [67, 70-72, 74], which may also tilt the system towards cleavage, according to results in the same SCA3/MJD transgenic mice as above, in which only the animals with higher full-length atxn3 expression displayed abundant levels of fragments [69]. It has been hypothesized that overexpressed atxn3 may be more susceptible to basal protease activity or that overexpression activates cell proteases [74]. Calpastatin levels, for example, are decreased upon expanded atxn3 overexpression [71].

Studies that analyze fragment formation by non-expanded and expanded forms of the protein in parallel, under the same condi- tions, usually do not underscore differences in the extent of cleavage resulting from polyQ expansion [70, 74]. In particular, results obtained in N2a cells indicated that human polyQ-expanded was not more sensitive to ionomycin-induced calpain-mediated cleavage than the non-expanded murine protein [68]. One exception are the observations obtained in the lentiviral rat models of SCA3/MJD, where atxn 3 fragments were found to be scarcer in brain tissue overexpressing non-expanded protein, compared with expression of the expanded protein [71]. In neuronal cultures derived from human iPSCs, atxn3 cleavage elicited upon glutamate stimulation was shown to occur in cells derived from healthy donors as well as patients, but the patient-derived neurons displayed several SDSinsoluble fragments that were absent from control samples [77]. It is thus hard to ascertain whether expanded atxn3 is more susceptible for proteolysis than the non-expanded protein or not. Another possibility supported by the study with human-derived neuronal cultures is that differences in processing may be more related to the topology of the fragments, i. e., the sites that are proteolyzed, rather than the extend of cleavage per se. Alternatively, the aggregateprone fragments may be more resistant to protein degradation.

Current literature generally agrees with the premise that expanded polyQ-containing fragments are more toxic than equivalent fragments with non-expanded glutamines. The studies describing increased aggregation and/or cytotoxicity associated with truncated atxn3 expression in cells and transgenic Drosophila report that these effects are not elicited $[61,69,89,90,92,98]$ by the corresponding truncations of the non-expanded protein. This fact strongly suggests that the factor responsible for turning atxn3 fragments toxic is the polyQ expansion. Consequently, regardless of the insufficiently supported idea that the expanded protein may be more susceptible to suffer proteolytic cleavage, the fragments that result from the expanded protein apparently elicit deleterious changes that are not provoked by the non-expanded fragments.

From these ideas arises the possibility that proteolytic cleavage of non-pathogenic atxn3 may be biologically relevant outside a disease context. The precise proteolytic processing of atxn 3 may play a role in the behavior of the protein in the cell and serve physiologic functions in which atxn3 is implicated. The separation of protein domains containing particular protein-interacting sites or localization signals, from one another or from the catalytic JD, may interfere with the molecular interactions established by the protein, with its deubiquitinase activity and with its cellular function, or with its susceptibility to be targeted by post-translational modifications. A profounder characterization of non-expanded endogenous atxn3 fragmentation, in the absence of stimuli that may deviate the system towards a particular outcome, may be a good starting point to address the possibility of an endogenous function for atxn3 cleavage.

\subsubsection{Toxicity of the N-Terminal Region of atxn3}

Evaluation of atxn3 fragment toxicity has mostly focused on the C-terminal part of the protein, in agreement with the causative importance of the expansion of the polyQ sequence therein contained, in the context of SCA3/MJD. Consequently, reports have usually investigated the behavior of C-terminal truncations of the protein and in doing so confirmed the toxicity of the C-terminal part of the expanded protein. Though results obtained in different studies agree on the increased toxic properties of these truncations, it is important to mention that truncation positions vary between studies, sometimes including no more than short sequences flanking the polyQ region [61]. Interestingly, those studies where truncations at different positions have been tested in parallel indicate that, the more $\mathrm{C}$-terminal is the truncation position, the more aggregateprone is the protein product $[75,89]$. Less extensive truncations do not elicit cell toxicity [89] or lead to the formation of detectable aggregates in vitro [75]. These considerations are in agreement with the toxicity of the expanded polyQ and, in fact, pure polyQ sequences appear to be as cytotoxic as the short $\mathrm{C}$-terminal frag- 
be as cytotoxic as the short C-terminal frag-ments [98], or even more [69]. The fact that purer polyQ sequences are more nefarious justifies the focus on the fragments containing glutamines and aligns with the hypothesis that the rest of atxn3 prevents against the toxicity of the expanded sequence. Proteolytic cleavage may trigger degeneration by removing this protection.

Proteolytic events that give rise to C-terminal fragments would also logically generate products that result from the $\mathrm{N}$-terminal part of the protein, some of which may constitute stable fragments. Reports have mentioned the detection of $\mathrm{N}$-terminal-derived fragments in transfected cells [67, 76], SCA3/MJD animal models [71, 72, 76] and human-derived neuronal cultures [77], considering fragment immunoreactivity against N-terminal-targeting antibodies or the fact that their molecular size is independent from the parental atxn3 glutamine length.

The considerations on polyQ-containing fragments notwithstanding, it is possible that the N-terminal part of the protein, likely containing the catalytic JD (considering their molecular size and the cleavage sites that have been predicted), may also operate toxic changes in the cell. The isolated JD is known to aggregate in vitro $[130,131]$ and the interaction of this domain with ubiquitin is hypothesized to prevent self-assembly [132]. The JD and the possible disturbance of its physiologic interactions have been predicted to play an important role in triggering the aggregation pathway of atxn3 [133]. According to this perspective, the regions outside the polyQ tract may predispose atxn3 to aggregation, and the expansion of the polyQ sequence precipitates the formation of highly stable amyloid aggregates [99].

The cytotoxicity of N-terminal truncations of atxn3 has not been characterized to the same extent as the cytotoxicity of Cterminal truncations. Interestingly, however, in a gene trap mouse model expressing a fusion protein that includes a $\mathrm{N}$-terminal portion of atxn3 (the JD and the first UIM), animals presented extranuclear neuronal inclusion bodies, neurodegenerative features and age-dependent motor symptoms, suggesting that putative fragments containing the N-terminal region of atxn3, possibly derived from proteolytic cleavage, may also induce toxicity [128]. Mice display an increased susceptibility to endoplasmic reticulum stress, which is putatively related with an impaired interaction between atxn 3 and $\mathrm{VCP} / \mathrm{p} 97$, since the region of atxn3 that is expressed partially mimics a putative calpain-derived fragment resulting from cleavage at position 260, that thereby lacks the region that interacts with $\mathrm{VCP} / \mathrm{p} 97$ [104]. The accumulation of this $\mathrm{N}$-terminal species in the cytoplasm is also in agreement with the expected outcome of the separation between localization signals as a consequence of cleavage occurring between the UIMs and the polyQ sequence. Though these results conflict in part with the relevance ascribed to polyQcontaining fragments supported by the majority of the available literature, they propone the need for a deeper characterization of the importance of $\mathrm{N}$-terminal fragments in the pathogenic cascade of SCA3/MJD.

\subsubsection{Atxn3 Proteolysis and the Regional Specificity of $S C A 3 / M J D$}

The ubiquitous expression of atxn3 in the organism [58, 79, $134,135]$ contrasts with the regional selectivity of neuronal degeneration observed in SCA3/MJD patients [9]. Atxn3 expression varies between different brain regions and cellular types, but increased transcript or protein levels do not correlate with the admitted specific vulnerability to degeneration $[10,16,58,79]$. The cause of the differential vulnerability to expanded atxn3 toxicity is yet to be understood, and it has been proposed that differences in the cellular context, perhaps operated by mechanisms such as post-translational modifications, may be at their root $[136,137]$.

Admitting that proteolytic cleavage is a factor contributing to expanded atxn 3 toxicity, it is possible that differences in basal protease activity or specifically of atxn3 proteolysis between different cell populations or brain regions underlie SCA3/MJD neuropathology $[69,98]$. Excluding the possible influence of different sample preparation and probing methodologies, the diversity in fragment detection between different studies certainly agrees with the idea that, in different cells types, atxn 3 may be proteolyzed in a diverse fashion and to different degrees. As a prominent example, Berke and collaborators reported that atxn 3 is proteolyzed in a cell-type dependent manner under apoptosis induction; depending on the cell culture in question (from different animal species) the same concentration of staurosporine could modestly reduce the levels of fulllength atxn 3 or completely eliminate the protein, and the appearance of detectable cleavage products would also vary [74]. In what regards to the nervous tissue, in Drosophila, atxn3 cleavage is more prominent when expression is generally directed at the nervous system than to the eye [70]. Moreover, both in transgenic mice (where full-length atxn3 expression is similar among regions analyzed) and human patients, an increased abundance of detectable fragments was described in regions known to be specially affected in SCA3/MJD [69]. Beyond absolute differences in the degree of atxn3 cleavage, it is possible that variation in proteolytic processing between different cell types may assume other facets, with various enzymes having different preponderance in the process and the resulting fragments displaying diverse topologies and exposing different regions.

In the aging human brain, several factors may increase the activity of proteases and thereby contribute to susceptibility of atxn3 to cleavage. Excitation-induced fragmentation and aggregation of atxn3 occurring in patient fibroblast-derived neurons was described to occur specifically in neurons, among the several cell types tested [77]. Atxn3 cleavage was suggested to be provoked by calcium influx through voltage-gated channels and subsequent activation of calpains, so it is possible that unbalanced excitatory activity may contribute to calpain activation and increased atxn3 proteolysis. Importantly, it has also been suggested that polyQ-expanded atx3 directly elicits a disturbance of calcium signaling, since the mutant protein (but not the non-expanded form) was found to associate with the intracellular calcium release channel type 1 inositol 1,4,5trisphosphate receptor $\left(\mathrm{InsP}_{3} \mathrm{R} 1\right)$ in cortical lysates of MJD model mice and to mediate InsP3-mediated calcium release [138]. The calcium signaling stabilizer dantrolene was shown to ameliorate phenotypic signs of the mouse model and reduce neuronal loss. Additionally, the increase in calpain activity believed to accompany aging [68, 139] may precipitate calcium-dependent proteolysis events as life progresses.

\subsection{Conclusion}

Atxn3 proteolysis has continuously attracted the attention of researchers focusing on the molecular basis of SCA3/MJD. Since the first in vitro experiments, several studies have been able to detect what is described as stable fragments, significant products of atxn3 cleavage deriving from the $\mathrm{C}$-terminal region of the protein as well the $\mathrm{N}$-terminal region, in diverse cell-based systems and animal models. Evidence suggests that atxn 3 may be processed by caspases (in particular caspase-1), calpains (calpain-2), or by a combination of their action, through a series of proteolytic events. Expanded atxn3-derived fragments display an enhanced toxicity, but since both non-expanded atxn 3 and the pathogenic form of the protein may be subjected to cleavage (possibly to similar degrees), it is probable that the expanded polyQ sequence is the factor that turns the C-terminal fragments deleterious to cells. The basis for their toxicity may lie on their increased tendency to aggregate and to accumulate in the nucleus and their ability to co-aggregate with non-fragmented atxn3, but may also involve alterations of atxn3 function and turnover. Overall, evidence suggests that atxn3 fragmentation plays a pivotal role in the molecular events leading to SCA3/MJD, by initializing or facilitating transitions in the pathogenic cascade. Considering that increased levels of atxn3 are associated with higher degrees of cleavage, aggregation and impaired 
degradation of the fragments, this may contribute to a loop that aggravates the situation. Results in animal models suggest that limiting atxn3 proteolysis may constitute a viable therapeutic strategy for SCA3/MJD. Given that pharmaceutical companies have developed calpain inhibitors, as part of their programs for other disorders - particularly Alzheimers disease - there is an opportunity to test these in pre-clinical models of MJD and potentially identify effective therapeutic drugs.

Though this vision of atxn 3 proteolysis is suggested and supported by the majority of available evidence, some of the ideas lack unanimous support. In Pozzi and collaborators' report of atxn3 cleavage in transfected COS-7 cells, human expanded atxn3 is proteolyzed to a lesser extent than non-expanded murine atxn3 [67]. This observation contrasts with the above, but does not contradict any of the main assumptions, since toxicity seems to be more related to the properties of the fragments produced than to the different ability for the expanded or non-expanded atxn3 to generate fragments. The authors nonetheless propose that the expansion of the polyQ sequence may mask cleavage sites and in this regard contribute to the accumulation of atxn3. Curiously, in this model fragments were generally found in both the nucleus and the cytoplasm and $\mathrm{N}$-terminal truncations had a predominantly cytoplasmic distribution. These observations may be related to specificities of this experimental model, in which SDS-resistant aggregates were also found only in the cytoplasm and inclusions were mainly perinuclear.

Mentions of atxn3 fragments' detection are not completely pervasive in SCA3/MJD literature concerning cellular and animal models of disease; many studies do not focus on this factor and others even underlie the absence of fragments. An earlier characterization of a CSM14.1 cell-based model stably expressing high levels of full-length expanded atxn3 was not able to detect the formation of any fragments that could be related with the toxicityassociated features reported [140]. Notably, some of the attempts at detecting atxn3 fragments in the brain of SCA3/MJD patients have also been unsuccessful [74]. Differences in fragments formation and thereby detection - may result from differences in proteolytic processing between experimental systems, and fragments bearing a particular epitope may be less stable in one system than in others, turning detection by an individual monoclonal antibody difficult [140]. Absence of fragment detection may also result from technical limitations. It is possible that particular epitopes end up being masked as a result of proteolysis or that pathogenesis-related events such as aggregation limit the solubility of the fragments and consequently hinder their detection [74].

All these considerations certainly support the need for a better characterization of atxn3 proteolysis, especially - and specifically in human-derived samples or in the experimental models that most closely mimic SCA3/MJD, such as neuronal-based systems or animal models. A thorough comprehension of the mechanisms mediating atxn3 cleavage and of the toxic action of the resulting fragments will surely contribute precious insights into SCA3/MJD pathogenesis.

\section{VOLTAGE-DEPENDENT P/Q-TYPE CALCIUM CHAN- NEL SUBUNIT ALPHA-1A AND SPINOCEREBELLAR ATAXIA TYPE 6}

Spinocerebellar ataxia type 6 (SCA6) is commonly regarded as being primarily a "pure" cerebellar disorder involving ataxia and dysarthria, though other type of signs may also be present in patients $[13,141]$. Pathology involves atrophy of the cerebellum and a relatively widespread neuronal loss, considered moderate when compared to that of other SCAs but that insides with particular severity upon Purkinje cells [13, 142-144]. The onset of the disease is also comparatively late and the symptoms' progression slow, being generally compatible with a normal life span [141,144].
SCA6 is associated with CAG expansion at the CACNA1A gene, which codifies isoform A of the alpha-1 subunit of voltagedependent calcium channels (VDCCs) - Cav2.1 [145]. Alpha-1 subunits constitute the pore-forming part of these protein complexes and guide calcium channel activity, thereby mediating cell functions that depend on calcium signaling such as neurotransmission and hormone release, as well as gene transcription and muscle contraction [146]. Specifically, subunit alpha-1A is expressed predominantly in the brain, where it constitutes some of the major presynaptic VDCCs involved in neurotransmission [147, 148]. Cav2.1 is primarily abundant in the cerebellum and establishes $P$ and/or Q-type calcium currents [148-150].

The CACNA1A gene includes numerous exons (47) and gives rise to diverse transcripts as a consequence of alternative splicing; the CAG repeat sequence is included only in the longest transcripts and consequently the polyQ tract is found only in the longest variants of the codified protein (the canonical form bearing $~ 2500$ amino acids) $[145,151]$. Interestingly, the CAG number threshold for disease is the shortest - 20-33 - among polyQ disorders [9]. Structurally, Cav2.1 is a membrane protein with four homologous transmembrane domains constituting the voltage-sensitive permeation pathway of the channel $[146,149]$. The polyQ region is located in the C-terminal region of the protein [99, 145], which faces the cytoplasm and participates in channel function regulation [149].

Contrary to other polyQ-containing proteins, the importance of Cav2.1's role in the nervous system is well established and is illustrated by the fact that Cav2.1-deficient mice rapidly develop severe ataxic features and seizures, before dying prematurely [152]. Additionally, point mutations of the CACNA1A gene have been associated with human neurological disorders other than SCA6, namely hemiplegic migraine type 1 and episodic ataxia type 2 [144] . However, whereas these diseases are admittedly caused by an altered channel activity $[153,154]$ or a loss-of-function [155] of the protein, respectively, a clear link between polyQ-expansion of Cav2.1 and aberrant changes of channel function is yet to be unanimously uncovered $[9,149]$. While some studies suggest alteration of the electrophysiological properties of expanded Cav2.1 channels upon polyQ expansion [156], some others have failed to observe substantial differences [157, 158], with discrepancies being admitted to result at least in part from differences existing between experimental systems [9].

It is possible that expanded Cav2.1 toxicity is the result of changes that are generally considered to be involved in every polyQ diseases, such as aggregation and the establishment of abnormal protein interactions [149]. Cav2.1 inclusions have been detected in the cerebellum of SCA6 patients, though principally in the cytoplasm (cell body and dendrites), in contrast with the other polyQ diseases [159-161]; curiously, small nuclear inclusions have been detected by the 1C2 anti-polyQ antibody, but not with a Cav2.1specific antibody [162]. The tendency of expanded Cav2.1 to aggregate when expanded is also attested by studies overexpressing the protein in cell line cultures $[159,160]$.

\subsection{Detection of Cav2.1-Derived Fragments}

Proteolytic cleavage of expanded Cav2.1 has been proposed to be a putative factor contributing to the toxic transitions causing SCA6. Different research groups have reported evidence suggesting that the C-terminal portion of Cav2.1 may be cleaved off of the protein, giving rise to a detectable polyQ-containing fragment. In HEK 293 cells and in the rat PC12 cell line, heterologous expression of non-expanded or expanded full-length human Cav2.1 ( 250 $\mathrm{kDa}$ ) gave rise to lower molecular weight species that were recognized by antibodies targeting the C-terminal part of the protein, their molecular sizes $(75-110 \mathrm{kDa})$ varying according to the polyQ length $[160,163,164]$. In mouse cerebellar lysates, a C-terminal 60 $\mathrm{kDa}$ species has also been detected and its lower molecular weight 
attributed to differences in Cav2.1 C-terminal region length existing between the two species [163].

In stably transfected HEK 293 T cells expressing Cav2.1, only the polyQ-expanded form produced a detectable $75 \mathrm{kDa}$ fragment [164]. Under these conditions the full-length protein was also not detected admittedly because HEK cells lack the other VDCC subunits that are required for removal of Cav2.1 from the endoplasmic reticulum and proper traffic to the plasma membrane [163, 165]. Authors suggested that detection of the fragment resulting from the expanded protein could be a consequence of its accumulation due to impaired degradation [164]. However, this was not the case in HEK 293 cells able to establish functional VDCCs by stably expressing the missing subunits. In this case, the detected levels of C-terminal fragments upon transfection with Cav2.1 were not dependent on polyQ sequence size $[163,164]$. Results are thus insufficient to sustain the hypothesis that polyQ length of Cav2.1 alters its tendency for cleavage and $\mathrm{C}$-terminal fragment yielding.

Support for the specific relevance of C-terminal fragments in the context of SCA6 derives from studies in human tissue samples. In human cerebellar extracts, labelling of Cav2.1 C-terminal revealed several protein products of lower molecular weight: 110 and $160 \mathrm{kDa}$ species that were admitted to result from alternative splicing, $75-85 \mathrm{kDa}$ products that were considered to correspond to the fragments detected in transfected cells cultures, and species with 25 and $37 \mathrm{kDa}$, also considered to be Cav2.1-derived fragments [160]. Though the $75-85 \mathrm{kDa}$ fragments were detected in cytoplasmic fractions of SCA6 patients and controls, in patients they were also present in nuclear fractions. SDS-insoluble material was only detected in patients and included the included the 75-85 kDa fragment, a smear possibly resulting from aggregation, but no obvious band corresponding to full-length protein. Fragments were also produced in other brain regions, but nuclear localization and insoluble accumulations were exclusive of the cerebellum.

\subsection{Toxicity of Cav2.1-Derived Fragments}

Several studies have demonstrated the toxicity of Cav2.1 Cterminal fragments in cell lines. PolyQ-containing truncations of Cav2.1 starting at amino acid 1776 were toxic to HEK 293T cells, causing cell death at increased levels than those caused by their full-length counterparts [164]. In these conditions, cell death levels were not influenced by polyQ sequence size. However, in VDCCestablishing HEK 293 cells and in granule neuron cultures expressing Cav2.1 truncations starting at amino acid 2096 (a predicted cleavage site) [163], as well as in COS-7 cells expressing a fusion protein formed by rat Cav2.1 C-terminal domains and the transmembrane CD4 receptor (enabling transport to membrane) [166] and in stably transfected HEK 293 cells under stress conditions, cell death levels were higher when the truncations included expanded glutamines [167], comparing to non-expanded fragments. Interestingly, in some of these studies shorter truncated products containing only the polyQ region and short flanking sequences were not sufficient to cause significant cell death even when expanded, admittedly because the expanded length of Cav2.1 (28 and 33, in these experiences) is relatively short, comparing to other polyQ diseasecausing proteins $[163,164]$. This indicates that other protein regions making up the $\mathrm{C}$-terminal fragments mediate the detected toxicity and reiterates the importance of the protein context in polyQ sequence-induced cell demise.

The toxicity of Cav2.1 fragments in vivo is attested by a recent report of transgenic mice expressing a $\mathrm{C}$-terminal truncated form of Cav2.1 containing the polyQ sequence with a pathogenic number of repeats $(27 \mathrm{Q})$ in Purkinje cells. Mice developed ataxic signs and age-dependent loss of Purkinje cells. Transgenic animals expressing a shorter $\mathrm{C}$-terminal truncation not deriving from the CAGcodifying exon also manifested ataxic signs but there was a better preservation of motor performance. Purkinje cell loss also occurred, but at later stages [168].

\subsection{Mechanisms of Cav2.1-Derived Fragment Toxicity}

As with the proteolytic cleavage of atxn3, characterization of the effects of Cav2.1 fragmentation has often pointed out an increase in aggregation tendency and/or shifts in subcellular localization as two putative mechanisms mediating toxicity.

In transfected PC12 cells, expression of a N-terminally truncated form of Cav2.1 starting at amino acid 1954 and containing expanded glutamines gave rise to detectable polyQ-positive inclusions in the cytoplasm (only), while none were detected when a non-expanded truncation or full-length Cav2.1 (with or without expansion) were expressed [160]. Curiously, however, in PC12 cells the $\mathrm{C}$-terminal fragments resulting from both non-expanded and expanded forms of recombinant full-length Cav2.1 formed oligomers detectable under mildly-denaturating conditions.

Unexpectedly, a particular antibody targeting the C-terminal of Cav2.1 has shown immunoreactivity in human cerebellar Purkinje cell nuclei, in contrast with another one targeting the N-terminal part of the protein, that only detected Cav2.1 in the membrane and cytoplasm [163], as generally expected of this membrane protein $[150,159]$. Agreeing observations made in VDCC-establishing HEK 293 cells and granule neuron cultures expressing the fulllength protein suggested that this nuclear localization was the result of cleavage of the C-terminal region from Cav2.1 and subsequent translocation [163]. Additionally, the $60 \mathrm{kDa}$ product from mouse cerebellar lysates and the $75 \mathrm{kDa}$ from transfected HEK 293 cells were substantially enriched in nuclear fractions, while the fulllength protein was nearly exclusive of cytoplasmic fractions [163].

Concerning the putative effect of polyQ expansion on nuclear localization of Cav2.1 fragments, in transfected PC12 cells, while full-length Cav2.1 and C-terminal fragments starting at amino acid 1954 are mainly cytoplasmic, the fragments were found also in the nucleus as well and their nuclear levels increased with larger numbers of glutamines $[160,169]$. What is more, C-terminal truncations starting at residue 1954 [167] or 2096 were strikingly enriched in the nucleus of HEK 293 cells, an effect that in the latter case was contingent upon three functional NLSs located N-terminally of the polyQ sequence [163]. Mutation of the NLSs decreased cell death caused by the polyQ-expanded truncation, informing that fragment toxicity may me related with its nuclear localization [163]. These results are consistent with the detection of nuclear Cav2.1 fragments exclusively in patients, mentioned above [160].

A recent study has nonetheless advocated the idea that the Cav2.1 fragments are more toxic when present in the cytoplasm [169]. In transfected PC12 cells, the 1954- recombinant C-terminal fragment of Cav2.1 elicited increased toxic when artificially targeted to the cytoplasm comparing with when directed at the nucleus, an effect that was more notorious in the case of the expanded protein. Targeting either non-expanded or expanded truncated Cav2.1 to the cytoplasm led also to the formation of inclusions. It was hypothesized that toxicity could arise from transcription factor sequestration, seeing as CREB was found to colocalize with the inclusions and its nuclear levels to be decreased, at least under expression of the polyQ-expanded truncation. The same study reported that, in Purkinje cells of SCA6 patients, CREB also colocalized with cytoplasmic polyQ-containing inclusions.

The comparison between the subcellular localization of the Cterminal truncation of Cav2.1 containing the polyQ sequence and the short, glutamine-lacking, truncation increased the dispute regarding the importance of nuclear versus cytoplasmic localization. In HEK 293 cells and in Purkinje cells from stereotaxically-injected mice, the polyQ-containing form constituted nuclear and cytoplasmic inclusions, while the shorter truncation was predominantly found in the nucleus, where it formed large inclusions [168]. 


\subsection{Conclusion}

Reports addressing the possibility of Cav2.1 cleavage playing a role in SCA6 generally agree on the fact that the full-length protein originates a C-terminal protein species, even when containing a non-expanded polyQ sequence. This may be indicative that cleavage and liberation of the C-terminal may have a physiologic function. C-terminal fragments are prone to aggregate and are cytotoxic in several cell-based systems and in vivo, their toxicity increasing with lengthier sequences of glutamines. Importantly, only in patients are they nuclear and constitute insoluble material possibly corresponding to aggregates. Fragmentation has been frequently related with the translocation of parts of Cav2.1 to the nucleus, but it is still unclear whether the fragments are more toxic in the nucleus or the cytoplasm.

Importantly, the putative enzymes responsible for cleaving Cav2.1 are still unknown. Taking into account sequence analysisbased predictions, Kordasiewicz and coworkers hypothesized that cleavage could be mediated by calpains, but they were unable to block Cav2.1 cleavage with calpain inhibitors, in HEK 293 cells [163].

It is conceivable that, independently of aggregation and changes in subcellular distribution, Cav2.1 cleavage may elicit toxicity by interfering with the function of P/Q-type VDCCs. The intercellular C-terminal portion of Cav2.1 is known to mediate protein interactions established by the channel complex and to regulate its activity [165]. Therefore, separation between this region and the other protein domains may have an impact on VDCCs function, possibly by deviating important protein interactions. For example, the $\mathrm{C}$ terminal region of Cav2.1 has been shown to interact directly with myosin IIB, which among other things participates in the sorting of plasma membrane proteins. Considering that, in COS-7 cells, glutamine expansion increased the stability of this interaction [166], retention of Cav2.1 at the membrane may be affected when the polyQ-expanded C-terminal region is lost.

There is also some evidence supporting that Cav2,1-derived fragments may cause deleterious changes in neurotransmission prior to cell death, in vivo. Overall, transgenic mice and lentiviral models expressing polyQ-expanded Cav2,1 C-terminal truncations display higher incidence of changes in Purkinje cell firing, comparing to controls and animals expressing the shorter, polyQ-lacking, truncation already mentioned [168]. An impairment of neuronal plasticity mechanisms at the parallel fiber-Purkinje cell synapse was also detected in the lentiviral model.

Conflicting with the role of proteolytic cleavage in generating a toxic C-terminal fragment of Cav2.1, a recent study has reported that the $75 \mathrm{kDa}$ protein species detected in HEK 293 cells expressing Cav2.1 (and possibly in other systems as well) may actually be the product of a second cistron contained in the CACNAIA gene [170]. Mass spectrometric sequencing of the fragment revealed that the N-terminus (amino acid 1960) did not overlap with any protease cleavage site, and further investigation demonstrated that the $\mathrm{C}$ terminal product could result from an internal ribosomal entry site present in the full-length Cav2.1 transcript. This cistronic product, termed $\alpha 1 \mathrm{ACT}$, was described to act as a transcription factor, binding to the genome, directing gene activation in Purkinje cells and enhancing neurite outgrowth in PC12 cells. The polyQ-expanded form of $\alpha 1 \mathrm{ACT}$ lacked the transcriptional function and the neurite outgrowth-mediating role, caused cell death in PC12 cells and produced age-dependent gait disturbances and cerebral atrophy in transgenic mice, compared to animals expressing non-expanded a1ACT. Regardless of the dispute concerning the origin of CACNA1A-derived C-terminal species, these results underlie the toxicity of the expanded polyQ-containing fragments and agree on the existence of a biologic role for the free $\mathrm{C}$-terminal domain that may be yielded upon cleavage.

\section{ATAXIN-7 AND SPINOCEREBELLAR ATAXIA TYPE 7}

In addition to ataxia and other neurological signs generally associated with polyQ-related SCAs, spinocerebellar ataxia type 7 (SCA7) distinctively causes a progressive impairment of the visual function, ultimately leading to blindness $[13,171]$. The disease involves cell loss in diverse regions of the central nervous system and an observable atrophy of the cortex and brainstem, but is also accompanied by degeneration of the retinal photoreceptors and the retinal pigment epithelium $[9,144]$. First symptoms typically manifest during adulthood [171].

SCA7 is caused by expansion of the ATXN7 gene beyond 33 CAG repetitions $[15,171,172]$. The particular instability of the CAG repeat tract of this gene accounts for some drastic examples of generational anticipation of disease manifestations and the large number of repeats carried by some SCA7 patients, unique among polyQ disorders $(>200)[9,173,174]$. The protein product ataxin-7 (atxn7) is widely, albeit varyingly, expressed in different neuronal and non-neuronal tissues and cell types [148, 175], being found both in the cytoplasm and the nucleus; the protein has been described to distribute diffusely in this last compartment, but to also associate with the nucleolus and the nuclear matrix [176, 177]. Although the precise physiologic function of atxn7 remains undefined, available evidence points to an involvement with transcriptional regulation and cytoskeleton organization [176, 178]. Atxn7 is an 892 amino acid protein and its polyQ stretch is localized in close proximity to the N-terminus $[99,151]$.

The toxicity of polyQ-expanded atxn7 has been suggested to arise as a consequence of alterations in important cell functions, namely transcription. Atxn7 is a component of the SPT3-TAF9GCN5 acetylase (STAGA) transcription coactivator-acetyltransferase complex, mediating the interaction of this complex with the transcription factor cone-rod homeobox protein (CRX), essential for photoreceptor maintenance [179]. Atxn7 plays a role in CRXdependent gene activation, by participating in histone acetylation and deubiquitination; when expanded, atxn7 represses activation of CRX, interfering with the expression of CRX-regulated genes in the retina $[180,181]$. In SCA7, protein deposition and nuclear inclusion formation is known to take place in the retina and in several regions of the brain that are not limited to the ones believed to be severely affected in the disease $[182,183]$.

\subsection{Detection of atxn7-Derived Fragments}

The role of proteolytic processing of atxn7 in the pathogenic mechanisms behind SCA7 is a frequently addressed topic. An initial report concerning transgenic mice expressing expanded atxn7 in rod photoreceptors or Purkinje cells remarked that age-dependent inclusions that appeared on par with other disease-related changes became progressively unreactive to $\mathrm{C}$-terminal-targeting antibodies, but not to a N-terminal-targeting one [184]. This led to the possibility that only a N-terminal fragment of atxn7 was recruited to the inclusions, and in fact a $\sim 120 \mathrm{kDa}$ polyQ-containing species was detected in extracts from animals expressing expanded atxn7 $(\sim 150$ $\mathrm{kDa})$. The overall detection of the C-terminal region of atxn7 faded with time in animals expressing the expanded protein, but not in animals expressing the non-expanded form. A later study of another transgenic mouse model expressing atxn7 obtained similar results with the nuclear inclusions and was able to detect a soluble $\mathrm{N}$ terminal fragment of atxn7 with $\sim 55 \mathrm{kDa}$, in transgenic mice expressing expanded atxn7, and a smaller one, in animals expressing the non-expanded atxn7 protein [185]. In the SCA7 transgenic mice, $\sim 55 \mathrm{kDa}$ fragments (that were absent from non-transgenic controls) were detected by the polyQ-specific 1C2 antibody, but were not exclusive of the nervous tissue, being present also in peripheral organs.

Importantly, a $1 \mathrm{C} 2$-immunoreactive $\sim 55 \mathrm{kDa}$ fragment was also detected in SCA7 patient fibroblasts, but not in controls; the detection of a single mRNA transcript in humans supports the hypothesis 
that these species were the result of proteolytic cleavage $[172,185]$. Recently, several atxn7 fragments have been detected in PC12 cells inducibly expressing human atxn7: one major fragment of 40-50 $\mathrm{kDa}$ resulting from non-expanded atxn7, and two major species, of 45 and $40 \mathrm{kDa}$, resulting from the expanded protein [186].

\subsection{Enzymes Involved in atxn7 Proteolysis}

In vitro-translated atxn 7 was cleaved by caspase-7 upon incubation with the recombinant enzyme, but not with several other caspases tested [187]. In these conditions, atxn7 originated three cleavage products, one with $\sim 70 \mathrm{kDa}$ and two that varied in molecular weight depending on the length of the polyQ stretch of the parental protein: 30 and $40 \mathrm{kDa}$ for non-expanded atxn7, and 45 $\mathrm{kDa}$ and $55 \mathrm{kDa}$, for the expanded form. These variations suggest that these last fragments included the polyQ-containing N-terminal region of the protein. The susceptibility to caspase-7-mediated cleavage was reportedly independent from polyQ length, however. Curiously, caspase-7 coimmunoprecipitated with atxn7 in transfected HEK 293T cells, with a notorious preference for the expanded protein. The fact that a caspase-7-derived fragment of expanded atxn2 comigrated with fragments detected in transgenic animal-derived samples supports the role of caspase- 7 in vivo [187, 188].

Atxn7 amino acid sequence contains two putative caspase-7 cleavage sites at D266 and D344. In vitro, mutation of D266 abrogated formation of the $30 / 45 \mathrm{kDa}$ product, mutation of D344 abolished the appearance of the $40 / 55 \mathrm{kDa}$ species, while double mutation completely blocked proteolysis by caspase-7. The double mutant also hindered the formation of fragments that took place in tamoxifen-treated HEK $293 \mathrm{~T}$ cells [187]. In a very recent study characterizing a transgenic mouse model expressing the cleavageresistant mutant $\mathrm{D} 266 \mathrm{~N}$ of expanded atxn7, this single mutation also blocked the formation of the $\sim 55 \mathrm{kDa}$ of atxn 7 ex vivo, in cerebellar lysates incubated with caspase-7 [189].

\subsection{Toxicity of atxn7-Derived Fragments}

The deleteriousness of polyQ-containing protein species deriving from atxn7 is supported by cell death evaluation in cells expressing C-terminally truncated atxn7. In transfected HEK 293T cells, a short atxn7 truncation containing expanded polyQ (and ending at amino acid 239) elicited the highest toxicity among other truncations and the full-length protein [187]. In SCA7 transgenic mice, appearance of fragments in nuclear aggregates correlated with the start of the disease-like phenotype [185].

Blocking caspase-7 proteolysis has also been proven beneficial in SCA7 models. Expression of a cleavage-resistant double mutant of expanded atxn7 in HEK 293 T cells completely blocked apoptotic cell death caused by expression of the toxic protein [187]. In transgenic mice, the D266N mutation rescued retinal degeneration and function and attenuated the motor abnormalities manifested by SCA7 transgenic mice expressing cleavable atxn7, suggesting that fragment formation may be necessary for disease-related signs to arise in the model [189].

\subsection{Mechanisms of atxn7-derived Fragment Toxicity}

In agreement with the expected propensity for proteins bearing expanded glutamines to aggregate, a polyQ-expanded truncated atxn7 mimicking cleavage at amino acid 266 had increased tendency to aggregate than its non-expanded counterpart, in transfected HEK 293T cells [190]. Importantly, however, the double caspase cleavage site mutant of expanded atxn7 led to a decreased formation of nuclear inclusions in COS-7 and HEK 293T cells, and completely abrogated inclusion formation in primary granule cell cultures [187]. This and the observations that only the N-terminal part of the protein tends to amass and be retained in inclusions [184, 185] may suggest that cleavage, admittedly by caspase-7, is an important step in the aggregation pathway.
Atxn7 has been described to contain one NES in the N-terminal region and three NLSs, one also in the N-terminal region and two in the C-terminal portion $[178,191,192]$. All these localization signals are localized C-terminally of the two predicted caspase sites and it is thus possible that caspase-7-mediated proteolysis of atxn7 alters the subcellular distribution of the polyQ-containing fragments by separating the targeting sequences from the polyQ-bearing part of the protein, with possible deleterious outcomes. Curiously, in PC12 cells inducibly expressing human atxn7, while the full-length transgenic protein was found mainly in the nucleus, fragments additionally occurred in the cytoplasm [186]. Atxn7 truncations containing amino acids 1-460 and thereby including not only the polyQ region but also the NES and the N-terminal NLS were less cytotoxic than truncations devoid of the localizing sequences and even than the full-length protein [187].

Atxn7 structure accommodates several regions predicted to mediate functional protein interactions, including a phosphatebinding (arrestin-like) site and a zinc-binding motif [178, 193]. The latter has been proposed to mediate the interaction between atxn7 and the STAGA complex and includes the predicted caspase cleavage site at D344. Additionally, the polyQ-containing region of atxn7 has also been described to mediate the interaction with CRX [192]. Conceivably, cleavage at the predicted positions may alter atxn7 interaction with the complex, and consequently interfere with its function. In a HEK $293 \mathrm{~T}$ cell-based gene reporter gene assay in which expanded full-length atxn7 led to a marked decrease in CRXmediated transcriptional activation, inhibiting cleavage by double mutation of the caspase-7 cleavage sites attenuated the effect, supporting a role for atxn 7 proteolysis in the transcriptional alterations that may be involved in the disease [187].

Combined observations collected in transfected HEK 293T and PC12 cells have suggested that full-length atxn7 and the resulting fragments may be differentially degraded. While the full-length protein seems to be mainly degraded by the ubiquitin-proteasome system, the fragments originating in these systems (especially those resulting from the expanded protein) and aggregated species are also degraded by autophagy. Autophagy inhibition in PC12 cells inducibly expressing expanded atxn7 resulted in increased aggregation and a decrease in cell viability [186]. Results also suggest that both the full-length expanded protein and resulting fragments are more stable, but their soluble levels tend to decrease, due to aggregation.

PolyQ expansion of atxn7-derived fragments may contribute to toxicity also by hindering their degradation. Truncations consisting of the first 266 amino acids of atxn7 have been shown to be degraded by macroautophagy in HEK 293T cells and cerebellar neuron cultures and their stability was described to be contingent upon the availability of lysine residues close to the cleavage site - K266 and K257 -, something that does not appear to be the case for fulllength atxn7 [190]. Post-translational modification of these residues, in particular acetylation, was suggested to block degradation and increase stability. Interestingly, polyQ-expanded fragments were determined to be resistant to autophagic degradation and more stable when the lysine residues are altered by mutation than the non-expanded forms, indicating that the turnover of the fragments may be altered upon polyQ expansion.

\subsection{Conclusion}

Proteolytic cleavage of atxn7 with subsequent production of detectable polyQ-containing fragments is supported by observations gathered from in vitro assays, cell-based systems and transgenic animal models. Caspase- 7 is pointed out as the enzyme mediating formation of the detected fragments, at least in vitro. N-terminal atxn7 fragments tend to accumulate in disease models, and in transfected cells the shortest polyQ truncations elicit the highest toxicity. Cleavage has been proposed to be significant in the events leading to aggregate formation, and to contribute to putatively toxic 
changes in the subcellular localization of atxn7, alterations of its transcriptional function and resistance to degradation.

Similarly to atxn3 and Cav2.1, atxn7 is apparently susceptible to proteolytic processing regardless of the polyQ sequence length. Again, this may be indicative that cleavage may play an important function in healthy cells and that expansion of the otherwise harmless fragments confers them their toxic properties. Remarkably though, apart from an increased tendency to aggregate and an improved stability $[187,190]$, the properties of the expanded polyQ fragments are yet to be further explored and distinguished from those of the non-expanded fragments.

Possibly arguing against a decisive contribution of atxn7 cleavage to SCA7 pathogenesis is the fact that, in animal models, fragments are also detected in non-neuronal tissues; expanded fragment production is thus not predictive of cell demise, in this context [185]. Curiously, however, systemic aggregation and heart pathology have been described in human SCA7 patients carrying extreme numbers of CAG repeats $[173,194]$. It is possible that toxicity of the fragments in peripheral organs only manifests with higher thresholds of CAG repeat number.

\section{OTHER TYPES OF POLYQ-ASSOCIATED SPINOCERE- BELLAR ATAXIAS}

The involvement of proteolytic cleavage in the pathogenic mechanisms of other polyQ-related SCAs has been occasionally hinted, but still lacks the same degree of support afforded to SCA3/MJD, SCA6 and SCA7. Although reports have mentioned the presence of detectable protein fragments in patients/and or models of SCA1, SCA2 and SCA17, available evidence is unsufficient to suggest any solid hypothesis regarding a toxic role in these diseases. Some studies have provided clues that point in the same directions as the ones focusing on SCA3/MJD, SCA6 and SCA7, but others have utterly dismissed the involvement of protein fragments. These subjects therefore remain to be fully explored. Further efforts aiming at detecting protein fragments and characterizing their properties in disease-relevant contexts may help clarify the current doubts.

\subsection{Ataxin-1 and Spinocerebellar Ataxia Type 1}

Spinocerebellar ataxia type 1 (SCA1) was the first ataxia for which a causative gene and protein were identified and characterized $[195,196]$. As for the other SCAs, the worldwide prevalence of the disease is very diverse, constituting one of the most frequent forms of autosomal dominant ataxia in South Africa and the Tohoku region of Japan, and one of the rarest forms in other parts of the world $[13,197]$. The clinical features of SCA1 include progressive limb and gait ataxia and other signs frequently associated with SCAs, such as dysphagia, oculomotor impairments, and pyramidal and extrapyramidal motor symptoms [198]. In most cases cognition is relatively spared, though general intellectual impairment is observed in advanced stages of the disease [199]. SCA1 primarily affects the brainstem, spinocerebellar tracts and cerebellar Purkinje cells, eliciting neuronal loss and marked atrophy of these areas [9].

Ataxin-1 (atxn1) is a $98 \mathrm{kDa}$ soluble protein with 815 amino acids codified by the $A T X N 1$ gene. The protein is widely expressed in the human body $[148,200]$ and its function has been linked to transcriptional repression [201]. In neurons the protein mostly displays a nuclear localization, contrasting with a cytosolic distribution in non-neuronal cells [200]. SCA1 is associated with CAG expansions beyond 39-40 repeats [9]. As for the other SCAs, neuronal intranuclear inclusions containing atxn 1 have been described in affected and non-affected brain regions of SCA1 patients [202] and toxicity is believed to require nuclear localization of the expanded protein [203].

One report has addressed, and dismissed, the possibility of proteolytic cleavage of atxn1 playing a role in SCA1 pathogenesis [203]. Atxn1-derived fragments with 70 and $40 \mathrm{kDa}$ were detected in the cerebellum of SCA1 transgenic mice expressing human atxn1. These protein species were detected with a C-terminaltargeting antibody and their molecular size did not vary with the polyQ length of the parental atxn1, in accordance with the $\mathrm{N}$ terminal localization of the polyQ sequence. However, complementary fragments that would be labelled with a N-terminal-specific antibody were not detected, presumably due to decreased stability. Inclusions formed in Purkinje cells were labelled by antibodies targeting epitopes at both extremities of atxn 1 and were admitted to contain the full-length protein. Finally, detection of the C-terminal fragments was reported to be unrelated with the appearance of disease signs of the model and suggested to be a side result from overexpression of the human atxn 1 in mice. It would be nonetheless worthy to elucidate whether the absence of polyQ-containing fragments detection could be related with decreased solubility and increased aggregation of these species.

\subsection{Ataxin-2 and Spinocerebellar Ataxia Type 2}

Spinocerebellar ataxia type 2 (SCA2) was first known as Wadia-Swami type ataxia, in reference to the two Indian researchers that first described the disorder [204], being renamed as SCA2 after the identification of ATXN2 as the affected gene [205-207]. Worldwide, it is considered the second most common form of autosomal dominant cerebellar ataxia [208], and the most prevalent form of ataxia in Mexico, Cuba (Holguín province) and eastern India [209-211]. The existence of large SCA2 families has also been reported in the UK, Spain, Australia, Germany, Italy and Brazil [212-214]. Clinically, SCA2 patients develop slow and progressive gait ataxia and dysarthria, together with visual impairments such as nystagmus and slow saccadic eye movements $[9,208]$. In most cases, the physical symptoms are accompanied by cognitive impairments and psychological dysfunctions [199, 208]. Neuropathologically, the most affected region is the cerebellum, but other regions such as the cerebral frontal lobes, the brainstem, some cranial nerves and the spinal cord are also compromised [9]. Neuronal loss targets the cerebellum (Purkinje cells and granular layer) as well as the brainstem and the substantia nigra, among other regions.

Ataxin-2 (atxn2) is a $140 \mathrm{KDa}$ protein with 1312 amino acid residues, ubiquitously expressed throughout the human organism $[148,205]$. Above 31 glutamine repeats atxn2 leads to the development of SCA2, and sub-threshold repeat lengths have also been associated with some cases of amyotrophic lateral sclerosis [215]. Atxn2 is mainly cytoplasmic and interacts directly with mRNA, promoting stability; its function has been linked to regulation of protein translation $[216,217]$. Inclusions in SCA2 patients have been detected both in the nucleus and the cytoplasm and, again, their distribution in the brain does not coincide with the described pattern of neurodegeneration [208, 217].

Two main atxn2 fragments have been detected in human cortical brain samples: an atxn2 fragment of $42 \mathrm{kDa}$ reactive to the polyQ-specific 1C2 antibody, and a $70 \mathrm{kDa}$ fragment, not labelled by the antibody [218]. Interestingly, the species of $42 \mathrm{kDa}$ (presumably $\mathrm{N}$-terminal, given the position of the polyQ region) was detected in a SCA2 patient and described to be practically absent from control samples, while the $70 \mathrm{kDa}$ product was detected in controls and in the same patient. A later study in SY5Y cells described five C-terminal atxn2 fragments: a robust one with $70 \mathrm{kDa}$, possibly corresponding to the above species, and four minor species [219]. Interestingly, in HEK $293 \mathrm{~T}$ cells transfected with atxn2 fusions, an additional band admittedly corresponding to a $\mathrm{N}$-terminal fragment equivalent to the $42 \mathrm{kDa}$ species was also noticeably detected in cells expressing polyQ-expanded atxn2, but was not abundant in cells expressing non-expanded atxn2 [218].

The fact that the polyQ-containing fragments are mentioned to be enriched in patient samples and that expansion appears to drive their detection suggests a link between atxn2 fragmentation and SCA2 pathogenesis. The actual extent of this link remains to be 
fully explored, but experiments with atxn2 truncations contrast with what has been obtained in similar evaluations of other polyQbearing proteins. In transfected COS-1 cells, cytotoxicity of a Nterminal truncation (amino acids 1-396) did not increase with increasing polyQ repeat lengths, contrary to what happened when full-length atxn2 was expanded [220]. N-terminal species were actually less deleterious than their full-length counterparts, with truncation virtually abolishing atxn2 toxicity. Additionally, truncated atxn2 remained diffusely distributed in the cytoplasm and did not form intracellular inclusions even when expanded. Consequently, in contrast with what has been hypothesized for other polyQ disease-causing proteins, results do not support the idea that atxn2 fragmentation and production of polyQ-containing fragments leads to a shift in subcellular localization or potentiates aggregation and cell loss. Atxn2 cleavage may affect its biologic function and intermolecular interactions through separation of protein domains [219], but observations nonetheless suggest that proteolytic processing does not potentiate toxicity.

\subsection{TATA-Box-Binding Protein and Spinocerebellar Ataxia Type 17}

Spinocerebellar ataxia type 17 (SCA17) is the most rare form of polyQ-associated autosomal dominant inherited ataxia and the most recently described [221, 222]. Clinically, disease presentation is highly heterogeneous and may involve a wide variety of often severe symptoms, ranging from motor impairments to psychiatric signs. SCA17 may include cerebellar signs but also features of a HD-like phenotype [223]. The brain of SCA17 patients typically shows atrophy and neuronal loss in the cerebellum, but a loss of cerebral cortical neurons has also been reported in some cases [224, 225].

CAG expansion causing SCA17 is associated with the TBP gene, which codifies the TATA-box-binding protein (TBP) [221]. TBP is a general transcription factor that plays a central role in the activation of eukaryotic genes, being expressed, in humans, throughout the body $[148,151,226]$. The protein exerts its function in the nucleus and has been detected in the relatively widespread intranuclear inclusions that occur in the brain of SCA17 patients [224]. Pathogenic CAG expansions, which in this case may be interrupted by CAA triplets, are considered to be included in the range of 43-63 repetitions [144, 225, 227].

The idea that alterations of TBP function underlie selective neuropathology in SCA17 is particularly puzzling taking into consideration the fundamental role of this protein in the cell [225]. Nevertheless, It has been reported that polyQ-expansion of TBP alters its interaction with other agents involved in transcription regulation and reduces binding to DNA [228, 229]. The polyQ region of TBP is contained in the N-terminal part of the protein, while the DNA-binding displays a C-terminal position [225, 229].

Initial studies were unable to detect in vitro proteolysis of TPB by purified caspases or by apoptotic cell extracts [25]. N-terminal fragments of TBP containing the polyQ region but lacking and intact DNA-binding domain have been detected in brain lysates from SCA17 transgenic mice expressing full-length human TBP, but not control wild-type animals [229]. Additionally, N-terminal species were suggested to have an increased propensity to aggregate: in HEK 293 cells transfected with expanded TBP, most aggregates labelled by an $\mathrm{N}$-terminal-targeting antibody were unreactive to antibodies targeting the $\mathrm{C}$-terminal region; in cultured cerebellar neurons from SCA17 mice the N-terminal antibody labelled nuclear inclusions, while the $\mathrm{C}$-terminal antibody yielded a diffuse nuclear signal. The putative aberrant properties of the TBP Nterminal fragments were further suggested by the fact that polyQexpanded TBP mutants with an internal deletion that hinders DNA binding were more prone to aggregate in the nucleus of HEK 293 cells than their non-mutated counterpart, inhibited transcription and displayed an atypical and substantial presence in the cytoplasm.
Detection of TBP fragments in human patient samples and a further characterization of the toxicity of cleaved TBP may endow further support to the involvement of proteolysis in SCA17 pathogenesis.

\section{CONCLUSION}

Among the six types of SCA caused by polyQ protein expansion, the putative contribution of proteolytic cleavage to disease pathogenesis is best characterized for SCA3/MJD, SCA6 and SCA7. Even for these disorders it is still challenging to try and draw any precise conclusion, but data overall supports the main ideas expressed by the "toxic fragment hypothesis". Atxn3, Cav2.1 and atxn7 originate stable - detectable - fragments and these species appear to be more deleterious than the corresponding fulllength proteins. Some noteworthy concepts arise from the detailed examination intended by this review.

First, though the idea of an involvement of proteolytic cleavage in polyQ disease pathology could suggest that the polyQ expansion is responsible for protein fragmentation phenomena that would be exclusive of a disease state, results demonstrate that proteins carrying a non-expanded polyQ sequence are also susceptible to cleavage. Current evidence is unsufficient to affirm that polyQ expansion increases the propensity for cleavage or that it alters the topology of proteolysis, so that a particular kind of fragment only arises when proteins are expanded. It is possible that the ability to distinguish the behavior of protein forms with different polyQ repeat lengths suffers with the strategies used to analyze cleavage; cleavage may be artificially driven by overexpression of the protein in some models, or from the experimental strategies used to elicit cleavage, in some cases. Observations in human subjects, under conditions as native as possible, are thus invaluable. Studies establishing correlations between fragment detection in human samples and disease help support the involvement of fragments, even if not in a causative way. Among polyQ-associated SCAs, examples of fragments detected in patients but not in controls have been documented for SCA3/MJD and SCA6, in brain samples, and for SCA7, in fibroblasts $[69,185,218]$.

Another concept that is more or less pervasive is that, though fragments may form from polyQ-containing proteins irrespectively of the repeat sequence size, expanded polyQ-containing fragments induce higher toxicity. This may constitute the most direct link between proteolysis and pathogenesis: protein fragments may be normally generated from polyQ-containing proteins, but their toxicity is dependent on their repeat size (Fig. 2).

$\mathrm{CAG} /$ polyQ expansion is considered the triggering factor in polyQ diseases considering that, apart from being the common feature of this group of disorders, symptoms' severity and precocity of disease onset correlate positively with repeat length and polyQ sequences expressed outside their natural contexts cause toxicity in diverse models $[10,15,20,230]$. Nonetheless, several arguments justify the interest in looking at each polyQ disease separately. Each of these diseases is accompanied by a diverse set of symptoms, cell demise affects different neuronal populations, age of disease onset varies between diseases and the repeat number threshold associated with toxicity is also dependent on the protein involved. All these differences admittedly ultimately stem from the same factor: the different protein context in which the polyQ sequence is inserted. In this perspective, the protein regions flanking the polyQ sequence are the ones responsible for specifying the disease outcomes $[9,10$, $14,15,20]$. Proteolytic cleavage logically changes this protein context, possible altering important localization signals or interaction surfaces, or removing regions that shield the protein against aggregation. The data discussed demonstrates how changes in the regions beyond the polyQ sequence influence toxicity. In general, the smaller the flanking regions are (the purest the polyQ), the more toxic is the protein product. However, truncation of Cav2.1 produces an interesting exception: toxicity is higher when the (short) polyQ region is flanked by shortened domains than when the flank- 


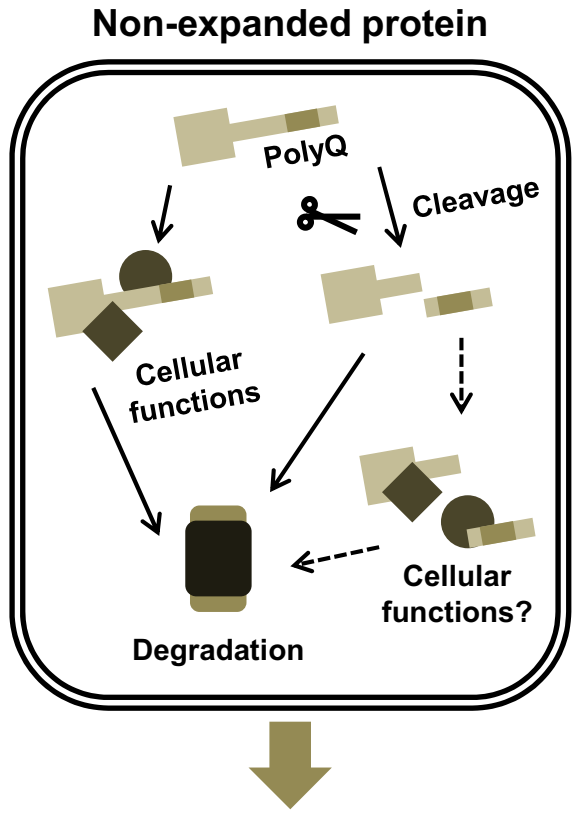

Healthy neuron

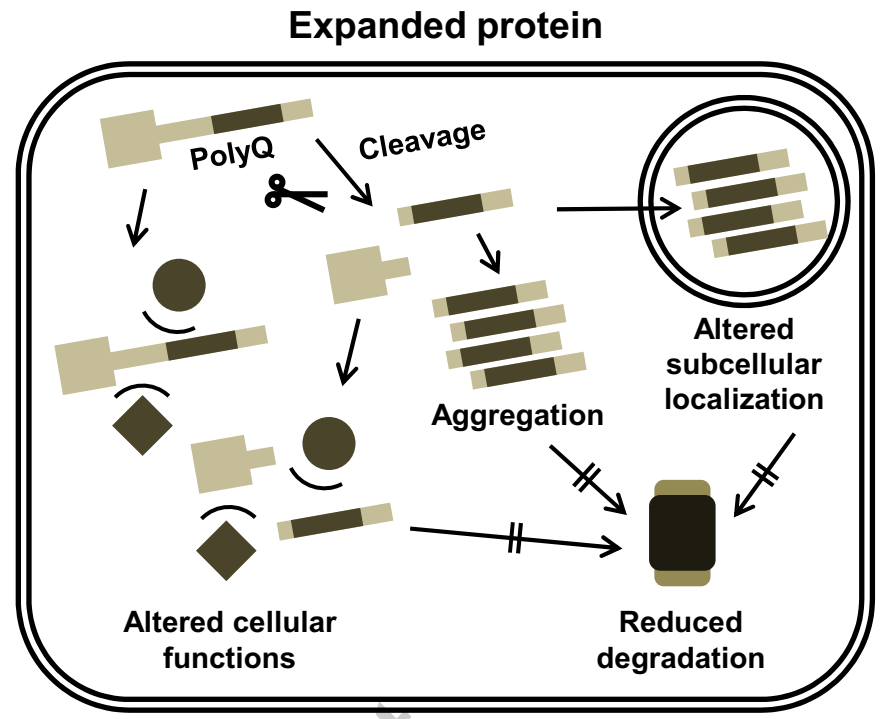

\section{Compromised neuron}

Fig. (2). Putative mechanisms of polyglutamine protein-derived fragment toxicity. Polyglutamine-containing proteins may be targeted by proteolytic cleavage as part of their normal dynamics in a cell, the fragments possibly playing biologically-relevant roles. In this context, proteins are expected to undergo standard degradation and experiment a normal turnover. When the proteins are pathogenically expanded, proteolytic cleavage may contribute to aberrant alterations of intermolecular interactions and functions, may drive aggregation and provoke aberrant shifts in subcellular localization. These abnormalities combined with a compromised degradation of the toxic protein products may contribute to cell dysfunction and loss associated with polyQ diseases.

ing regions are almost completely absent. This is instrumental evidence of the role of protein context and implies that, although a search for common disease mechanisms is justified, particular aspects of each protein are sure to have relevance for cellular function and survival, thereby determining cell fate in the presence of an expanded polyQ sequence.

The importance of subcellular localization shifts occurring in the wake of protein cleavage is somewhat disparate, and results recommend a case-by-case analysis. While there is a recurrent theme of toxic translocation of fragments to (or retention in) the nucleus, fragmented atxn7, for example, appears to shift to the cytoplasm. While accumulation of proteins in the nucleus may play an important part in several polyQ diseases, disturbances of subcellular localization may have a deleterious effects regardless of the compartment to which proteins are displaced.

The studies hereby considered advise caution when admitting that a particular species of lower molecular weight is to be considered a proteolytic fragment. Protein species that are detected by polyQ protein-targeting antibodies may instead correspond to protein variants, possibly resulting from alternative splicing or from alternative modes of transcription [170, 231]. Species that are not detected when putative cleavage sites are mutated or that definitely result from just one gene transcript may be more confidently considered proteolytic fragments, but even among these species some may be more biologically significant than others.

Available data overall supports the interest in delving deeper into the proteolytic cleavage of polyQ disease-causing proteins. Many scientific fields concerned with neurodegenerative diseases would benefit from a better understanding of the role of fragmentation in polyQ diseases, the circumstances under which these processes occur, the possible physiologic function of fragmentation of the non-expanded proteins and the mechanisms and enzymatic agents responsible for cleavage. In particular, understanding the spatial pattern of fragmentation may yield important clues into the

reasons behind selective neuronal loss. Current evidence suggests that limiting cleavage of polyQ-containing proteins may constitute a beneficial strategy to tackle expanded polyQ protein toxicity in the context of neurodegenerative diseases. In this respect, targeting a particular cleavage event with sufficient specificity will surely attract the attention of future research.

\section{LIST OF ABBREVIATIONS}

$\mathrm{AD}$

ALLN

APP

atxn1

atxn2

atxn3

atxn7

Cav2.1

CBP

CHIP

CREB

CRX

DRPLA

HD

HEK

HHR23A/B
$=$ Alzheimer's disease

$=\mathrm{N}$-acetyl-L-leucyl-L-leucyl-leucyl-Lnorleucinal

$=$ Amyloid precursor protein

$=$ Ataxin -1

$=$ Ataxin -2

$=$ Ataxin -3

$=$ Ataxin -7

$=$ Voltage-dependent $\mathrm{P} / \mathrm{Q}$-type calcium channel subunit alpha-1A

$=$ CREB-binding protein

$=\mathrm{C}$-terminus of $70 \mathrm{kDa}$ heat shock proteininteracting protein

$=$ Cyclic AMP-responsive element-binding protein

$=$ Cone-rod homeobox protein

$=$ Dentatorubral-pallidoluysian atrophy

$=$ Huntington's disease

$=$ Human embryonic kidney

$=$ Human homologs of the yeast DNA repair protein $\operatorname{Rad} 23 \mathrm{~A}$ and $\mathrm{B}$ 


\begin{tabular}{|c|c|c|}
\hline $\mathrm{InsP}_{3} \mathrm{R} 1$ & $=$ & $\begin{array}{l}\text { Type } 1 \text { inositol 1,4,5-trisphosphate recep- } \\
\text { tor }\end{array}$ \\
\hline iPSCs & $=$ & Induced pluripotent stem cells \\
\hline JD & $=$ & Josephin domain \\
\hline $\mathrm{kDa}$ & $=$ & Kilodalton \\
\hline MJD & $=$ & Machado-Joseph disease \\
\hline NEDD8 & $=$ & $\begin{array}{l}\text { Neural precursor cell expressed develop- } \\
\text { mentally downregulated gene } 8\end{array}$ \\
\hline NES & $=$ & Nuclear export signal \\
\hline NLS & $=$ & Nuclear localization signal \\
\hline PCAF & $=$ & p300/CBP-associated factor \\
\hline polyQ & $=$ & Polyglutamine \\
\hline SBMA & $=$ & Spinal and bulbar muscular atrophy \\
\hline SCA & $=$ & Spinocerebellar ataxia \\
\hline $\mathrm{SCA} 1,2,3,6,7,17$ & $=$ & $\begin{array}{l}\text { Spinocerebellas ataxia type } 1,2,3,6,7 \\
\text { and } 17\end{array}$ \\
\hline STAGA & $=$ & SPT3-TAF9-GCN5 acetylase \\
\hline TBP & $=$ & TATA-box-binding protein \\
\hline TR-FRET & $=$ & $\begin{array}{l}\text { Time-resolved Förster resonance energy } \\
\text { transfer }\end{array}$ \\
\hline UIM & $=$ & Ubiquitin-interacting motif \\
\hline $\mathrm{VCP}$ & $=$ & Valosin-containing protein \\
\hline VDCC & $=$ & Voltage-dependent calcium channel \\
\hline zVAD-fmk & $=$ & $\begin{array}{l}\text { Carbobenzoxy-valyl-analyl-aspastyl-[O- } \\
\text { methyl]-fluoromethylketone. }\end{array}$ \\
\hline
\end{tabular}

\section{CONFLICT OF INTEREST}

The authors confirm that this article content has no conflict of interest.

\section{ACKNOWLEDGEMENTS}

Authors' laboratory is supported by FEDER (CENTRO-07ST24-FEDER-002002) through the Competitive Factors Operational Program-COMPETE and National Funds (PIDDAC), Portuguese Foundation for Science and Technology (FCT), strategic project UID/NEU/ 04539/2013, E-Rare4/0003/2012 Joint call for European Research Project on Rare Diseases, French Muscular Dystrophy Association (AFM), the National Ataxia Foundation (NAF) and Richard Chin and Lily Lock Machado-Joseph disease Research Fund. CAM is supported by the 01/BIDJPND Synspread/2016 project. CN is supported by the Portuguese Science Foundation (FCT) and by The French Muscular Dystrophy Association (AFM). All authors contributed to the current literature review.

\section{REFERENCES}

[1] Esler WP, Wolfe MS. A portrait of Alzheimer secretases--new features and familiar faces. Science 2001; 293: 1449-54.

[2] Kayed R, Head E, Thompson JL, et al. Common structure of soluble amyloid oligomers implies common mechanism of pathogenesis. Science 2003; 300: 486-9.

[3] Galvan V, Gorostiza OF, Banwait S, et al. Reversal of Alzheimer'slike pathology and behavior in human APP transgenic mice by mutation of Asp664. Proc Natl Acad Sci USA 2006; 103: 7130-5.

[4] Gamblin TC, Chen F, Zambrano A, et al. Caspase cleavage of tau: linking amyloid and neurofibrillary tangles in Alzheimer's disease. Proc Natl Acad Sci USA 2003; 100: 10032-7.

[5] Newman J, Rissman RA, Sarsoza F, et al. Caspase-cleaved tau accumulation in neurodegenerative diseases associated with tau and alpha-synuclein pathology. Acta Neuropathol 2005; 110: 135-44.

[6] Games D, Valera E, Spencer B, et al. Reducing C-terminaltruncated alpha-synuclein by immunotherapy attenuates neurodegeneration and propagation in Parkinson's disease-like models. J Neurosci 2014; 34: 9441-54.
[7] Li W, West N, Colla E, et al. Aggregation promoting C-terminal truncation of alpha-synuclein is a normal cellular process and is enhanced by the familial Parkinson's disease-linked mutations. Proc Natl Acad Sci USA 2005; 102: 2162-7.

[8] Walker LC, LeVine H. The cerebral proteopathies: neurodegenerative disorders of protein conformation and assembly. Mol Neurobiol 2000; 21: 83-95.

[9] Rüb U, Schöls L, Paulson H, et al. Clinical features, neurogenetics and neuropathology of the polyglutamine spinocerebellar ataxias type 1, 2, 3, 6 and 7. Prog Neurobiol 2013; 104: 38-66.

[10] Zoghbi HY, Orr HT. Glutamine repeats and neurodegeneration. Annu Rev Neurosci 2000; 23: 217-47.

[11] Cummings CJ, Zoghbi HY. Fourteen and counting: unraveling trinucleotide repeat diseases. Hum Mol Genet 2000; 9: 909-16.

[12] Durr A. Autosomal dominant cerebellar ataxias: polyglutamine expansions and beyond. Lancet Neurol 2010; 9: 885-94.

[13] Schöls L, Bauer P, Schmidt T, Schulte T, Riess O. Autosomal dominant cerebellar ataxias: clinical features, genetics, and pathogenesis. Lancet Neurol 2004; 3: 291-304.

[14] Gatchel JR, Zoghbi HY. Diseases of unstable repeat expansion: mechanisms and common principles. Nat Rev Genet 2005; 6: 743-55.

[15] Williams AJ, Paulson HL. Polyglutamine neurodegeneration: protein misfolding revisited. Trends Neurosci 2008; 31: 521-8.

[16] Bauer PO, Nukina N. The pathogenic mechanisms of polyglutamine diseases and current therapeutic strategies. J Neurochem 2009; 110: 1737-65.

[17] La Spada AR, Taylor JP. Repeat expansion disease: progress and puzzles in disease pathogenesis. Nat Rev Genet 2010; 11: 247-58.

[18] Shao J, Diamond MI. Polyglutamine diseases: emerging concepts in pathogenesis and therapy. Hum Mol Genet 2007; 16 Spec No. 2: R115-23.

[19] Todd TW, Lim J. Aggregation formation in the polyglutamine diseases: protection at a cost? Mol Cells 2013; 36: 185-94.

[20] Takahashi T, Katada S, Onodera O. Polyglutamine diseases: where does toxicity come from? what is toxicity? where are we going? J Mol Cell Biol 2010; 2: 180-91.

[21] Hands S, Sinadinos C, Wyttenbach A. Polyglutamine gene function and dysfunction in the ageing brain. Biochim Biophys Acta 2008; 1779: 507-21.

[22] Ferrigno P, Silver PA. Polyglutamine expansions: proteolysis, chaperones, and the dangers of promiscuity. Neuron 2000;26: 9-12.

[23] Tarlac V, Storey E. Role of proteolysis in polyglutamine disorders. J Neurosci Res 2003; 74: 406-16.

[24] Walsh R, Storey E, Stefani D, Kelly L, Turnbull V. The roles of proteolysis and nuclear localisation in the toxicity of the polyglutamine diseases. A review. Neurotox Res 2005; 7: 43-57.

[25] Wellington CL, Ellerby LM, Hackam AS, et al. Caspase cleavage of gene products associated with triplet expansion disorders generates truncated fragments containing the polyglutamine tract. J Biol Chem 1998; 273: 9158-67.

[26] Ellerby LM, Andrusiak RL, Wellington CL, et al. Cleavage of atrophin-1 at caspase site aspartic acid 109 modulates cytotoxicity. J Biol Chem 1999; 274: 8730-6.

[27] Butler R, Leigh PN, McPhaul MJ, Gallo JM. Truncated forms of the androgen receptor are associated with polyglutamine expansion in X-linked spinal and bulbar muscular atrophy. Hum Mol Genet 1998; $7:$ : 121-7.

[28] Gafni J, Hermel E, Young JE, Wellington CL, Hayden MR, Ellerby LM. Inhibition of calpain cleavage of huntingtin reduces toxicity: accumulation of calpain/caspase fragments in the nucleus. J Biol Chem 2004; 279: 20211-20.

[29] Schilling G, Wood JD, Duan K, et al. Nuclear accumulation of truncated atrophin-1 fragments in a transgenic mouse model of DRPLA. Neuron 1999; 24: 275-86.

[30] Li M, Chevalier-Larsen ES, Merry DE, Diamond MI. Soluble androgen receptor oligomers underlie pathology in a mouse model of spinobulbar muscular atrophy. J Biol Chem 2007; 282: 3157-64.

[31] Landles C, Sathasivam K, Weiss A, et al. Proteolysis of mutant huntingtin produces an exon 1 fragment that accumulates as an aggregated protein in neuronal nuclei in Huntington disease. $\mathrm{J}$ Biol Chem 2010; 285: 8808-23.

[32] Bayram-Weston Z, Jones L, Dunnett SB, Brooks SP. Light and electron microscopic characterization of the evolution of cellular 
pathology in YAC128 Huntington's disease transgenic mice. Brain Res Bull 2012; 88: 137-47.

[33] Li M, Miwa S, Kobayashi Y, et al. Nuclear inclusions of the androgen receptor protein in spinal and bulbar muscular atrophy. Ann Neurol 1998; 44: 249-54.

[34] DiFiglia M, Sapp E, Chase KO, et al. Aggregation of huntingtin in neuronal intranuclear inclusions and dystrophic neurites in brain. Science 1997; 277: 1990-3.

[35] Mende-Mueller LM, Toneff T, Hwang SR, Chesselet MF, Hook VY. Tissue-specific proteolysis of Huntingtin (htt) in human brain: evidence of enhanced levels of $\mathrm{N}$ - and C-terminal htt fragments in Huntington's disease striatum. J Neurosci 2001; 21: 1830-7.

[36] Kim YJ, Yi Y, Sapp E, et al. Caspase 3-cleaved N-terminal fragments of wild-type and mutant huntingtin are present in normal and Huntington's disease brains, associate with membranes, and undergo calpain-dependent proteolysis. Proc Natl Acad Sci USA 2001; 98: 12784-9.

[37] Nucifora FC, Jr., Ellerby LM, Wellington CL, et al. Nuclear localization of a non-caspase truncation product of atrophin-1, with an expanded polyglutamine repeat, increases cellular toxicity. $\mathrm{J}$ Biol Chem 2003; 278: 13047-55

[38] Merry DE, Kobayashi Y, Bailey CK, Taye AA, Fischbeck KH. Cleavage, aggregation and toxicity of the expanded androgen receptor in spinal and bulbar muscular atrophy. Hum Mol Genet 1998; 7: 693-701.

[39] Young JE, Garden GA, Martinez RA, et al. Polyglutamineexpanded androgen receptor truncation fragments activate a Baxdependent apoptotic cascade mediated by DP5/Hrk. J Neurosci 2009; 29: 1987-97.

[40] Graham RK, Deng Y, Slow EJ, et al. Cleavage at the caspase-6 site is required for neuronal dysfunction and degeneration due to mutant huntingtin. Cell 2006; 125: 1179-91.

[41] Mangiarini L, Sathasivam K, Seller M, et al. Exon 1 of the HD gene with an expanded CAG repeat is sufficient to cause a progressive neurological phenotype in transgenic mice. Cell 1996; 87: 493-506.

[42] Milnerwood AJ, Gladding CM, Pouladi MA, et al. Early increase in extrasynaptic NMDA receptor signaling and expression contributes to phenotype onset in Huntington's disease mice. Neuron 2010; 65: 178-90

[43] Cooper JK, Schilling G, Peters MF, et al. Truncated N-terminal fragments of huntingtin with expanded glutamine repeats form nuclear and cytoplasmic aggregates in cell culture. Hum Mol Genet 1998; 7: 783-90

[44] Ellerby LM, Hackam AS, Propp SS, et al. Kennedy's disease: caspase cleavage of the androgen receptor is a crucial event in cytotoxicity. J Neurochem 1999; 72: 185-95.

[45] Igarashi S, Koide R, Shimohata T, et al. Suppression of aggregate formation and apoptosis by transglutaminase inhibitors in cells expressing truncated DRPLA protein with an expanded polyglutamine stretch. Nat Genet 1998; 18: 111-7.

[46] Feng B, Chen L, Drmanovic Z, et al. Intracellular processing and toxicity of the truncated androgen receptor: nuclear congophiliaassociated cell death. J Neuropathol Exp Neurol 2000; 59: 652-63.

[47] Miyashita T, Nagao K, Ohmi K, Yanagisawa H, Okamura-Oho Y, Yamada M. Intracellular aggregate formation of dentatorubralpallidoluysian atrophy (DRPLA) protein with the extended polyglutamine. Biochem Biophys Res Commun 1998; 249: 96-102.

[48] Wellington CL, Ellerby LM, Gutekunst CA, et al. Caspase cleavage of mutant huntingtin precedes neurodegeneration in Huntington's disease. J Neurosci 2002; 22: 7862-72.

[49] Kobayashi Y, Miwa S, Merry DE, et al. Caspase-3 cleaves the expanded androgen receptor protein of spinal and bulbar muscular atrophy in a polyglutamine repeat length-dependent manner. Biochem Biophys Res Commun 1998; 252: 145-50.

[50] Sun B, Fan W, Balciunas A, et al. Polyglutamine repeat lengthdependent proteolysis of huntingtin. Neurobiol Dis 2002; 11: 111-22.

[51] Martins S, Calafell F, Gaspar C, et al. Asian origin for the worldwide-spread mutational event in Machado-Joseph disease. Arch Neurol 2007; 64: 1502-8

[52] Bettencourt C, Lima M. Machado-Joseph Disease: from first descriptions to new perspectives. Orphanet J Rare Dis 2011; 6: 35.

[53] Pedroso JL, Franca MC, Jr., Braga-Neto P, et al. Nonmotor and extracerebellar features in Machado-Joseph disease: a review. Mov Disord 2013; 28: 1200-8.
[54] Lopes TM, D'Abreu A, Franca MC, Jr., et al. Widespread neuronal damage and cognitive dysfunction in spinocerebellar ataxia type 3 . J Neurol 2013; 260: 2370-9.

[55] Kawaguchi Y, Okamoto T, Taniwaki M, et al. CAG expansions in a novel gene for Machado-Joseph disease at chromosome 14q32.1. Nat Genet 1994; 8: 221-8.

[56] Matos CA, de Macedo-Ribeiro S, Carvalho AL. Polyglutamine diseases: the special case of ataxin-3 and Machado-Joseph disease. Prog Neurobiol 2011; 95: 26-48.

[57] Masino L, Musi V, Menon RP, et al. Domain architecture of the polyglutamine protein ataxin-3: a globular domain followed by a flexible tail. FEBS Lett 2003; 549: 21-5.

[58] Trottier Y, Cancel G, An-Gourfinkel I, et al. Heterogeneous intracellular localization and expression of ataxin-3. Neurobiol Dis 1998; 5: 335-47.

[59] Macedo-Ribeiro S, Cortes L, Maciel P, Carvalho AL. Nucleocytoplasmic shuttling activity of ataxin-3. PLoS One 2009; 4: e5834.

[60] Schmidt T, Landwehrmeyer GB, Schmitt I, et al. An isoform of ataxin-3 accumulates in the nucleus of neuronal cells in affected brain regions of SCA3 patients. Brain Pathol 1998; 8: 669-79.

[61] Paulson HL, Perez MK, Trottier Y, et al. Intranuclear inclusions of expanded polyglutamine protein in spinocerebellar ataxia type 3 . Neuron 1997; 19: 333-44.

[62] Riess O, Rüb U, Pastore A, Bauer P, Schöls L. SCA3: neurological features, pathogenesis and animal models. Cerebellum 2008; 7(2): 125-37

[63] Bichelmeier U, Schmidt T, Hubener J, et al. Nuclear localization of ataxin-3 is required for the manifestation of symptoms in SCA3: in vivo evidence. J Neurosci 2007; 27: 7418-28.

[64] Perez MK, Paulson HL, Pittman RN. Ataxin-3 with an altered conformation that exposes the polyglutamine domain is associated with the nuclear matrix. Hum Mol Genet 1999; 8: 2377-85.

[65] Seidel K, den Dunnen WF, Schultz C, et al. Axonal inclusions in spinocerebellar ataxia type 3. Acta Neuropathol 2010; 120: 449-60.

[66] Seidel K, Siswanto S, Fredrich M, et al. On the Distribution of Intranuclear and Cytoplasmic Aggregates in the Brainstem of Patients with Spinocerebellar Ataxia Type 2 and 3. Brain Pathol 2016.

[67] Pozzi C, Valtorta M, Tedeschi G, et al. Study of subcellular localization and proteolysis of ataxin-3. Neurobiol Dis 2008; 30: 190-200

[68] Haacke A, Hartl FU, Breuer P. Calpain inhibition is sufficient to suppress aggregation of polyglutamine-expanded ataxin-3. J Biol Chem 2007; 282: 18851-6.

[69] Goti D, Katzen SM, Mez J, et al. A mutant ataxin-3 putativecleavage fragment in brains of Machado-Joseph disease patients and transgenic mice is cytotoxic above a critical concentration. J Neurosci 2004; 24: 10266-79.

[70] Jung $\mathrm{J}, \mathrm{Xu} \mathrm{K}$, Lessing D, Bonini NM. Preventing Ataxin-3 protein cleavage mitigates degeneration in a Drosophila model of SCA3. Hum Mol Genet 2009; 18: 4843-52.

[71] Simões AT, Goncalves N, Koeppen A, et al. Calpastatin-mediated inhibition of calpains in the mouse brain prevents mutant ataxin 3 proteolysis, nuclear localization and aggregation, relieving Machado-Joseph disease. Brain 2012; 135: 2428-39.

[72] Simões AT, Goncalves N, Nobre RJ, Duarte CB, Pereira de Almeida L. Calpain inhibition reduces ataxin-3 cleavage alleviating neuropathology and motor impairments in mouse models of Machado-Joseph disease. Hum Mol Genet 2014; 23(18): 4932-44.

[73] Colomer Gould VF, Goti D, Pearce D, et al. A mutant ataxin-3 fragment results from processing at a site $\mathrm{N}$-terminal to amino acid 190 in brain of Machado-Joseph disease-like transgenic mice. Neurobiol Dis 2007; 27: 362-9.

[74] Berke SJ, Schmied FA, Brunt ER, Ellerby LM, Paulson HL. Caspase-mediated proteolysis of the polyglutamine disease protein ataxin-3. J Neurochem 2004; 89: 908-18.

[75] Haacke A, Broadley SA, Boteva R, Tzvetkov N, Hartl FU, Breuer P. Proteolytic cleavage of polyglutamine-expanded ataxin-3 is critical for aggregation and sequestration of non-expanded ataxin-3. Hum Mol Genet 2006; 15: 555-68

[76] Hübener J, Weber JJ, Richter C, et al. Calpain-mediated ataxin-3 cleavage in the molecular pathogenesis of spinocerebellar ataxia type 3 (SCA3). Hum Mol Genet 2013; 22: 508-18.

[77] Koch P, Breuer P, Peitz M, et al. Excitation-induced ataxin-3 aggregation in neurons from patients with Machado-Joseph disease. Nature 2011; 480: 543-6. 
[78] Bettencourt C, Santos C, Montiel R, et al. Increased transcript diversity: novel splicing variants of Machado-Joseph disease gene (ATXN3). Neurogenetics 2009; 11: 193-202.

[79] Ichikawa Y, Goto J, Hattori M, et al. The genomic structure and expression of MJD, the Machado-Joseph disease gene. J Hum Genet 2001; 46: 413-22.

[80] Salvesen GS, Hempel A, Coll NS. Protease signaling in animal and plant-regulated cell death. FEBS J 2016; 283(14): 2577-98.

[81] Baudry M, Bi X. Calpain-1 and Calpain-2: The Yin and Yang of Synaptic Plasticity and Neurodegeneration. Trends Neurosci 2016; 39: $235-45$.

[82] Berke SJ, Chai Y, Marrs GL, Wen H, Paulson HL. Defining the role of ubiquitin-interacting motifs in the polyglutamine disease protein, ataxin-3. J Biol Chem 2005; 280: 32026-34.

[83] Colomer Gould VF. Mouse models of spinocerebellar ataxia type 3 (Machado-Joseph disease). Neurotherapeutics 2012; 9: 285-96.

[84] Lin KI, Baraban JM, Ratan RR. Inhibition versus induction of apoptosis by proteasome inhibitors depends on concentration. Cell Death Differ 1998; 5: 577-83.

[85] An WG, Hwang SG, Trepel JB, Blagosklonny MV. Protease inhibitor-induced apoptosis: accumulation of wt p53, p21WAF1/CIP1, and induction of apoptosis are independent markers of proteasome inhibition. Leukemia 2000; 14: 1276-83.

[86] Mauri PL, Riva M, Ambu D, et al. Ataxin-3 is subject to autolytic cleavage. FEBS J 2006; 273: 4277-86.

[87] Ikeda H, Yamaguchi M, Sugai S, Aze Y, Narumiya S, Kakizuka A. Expanded polyglutamine in the Machado-Joseph disease protein induces cell death in vitro and in vivo. Nat Genet 1996; 13: 196-202.

[88] Perez MK, Paulson HL, Pendse SJ, Saionz SJ, Bonini NM, Pittman $\mathrm{RN}$. Recruitment and the role of nuclear localization in polyglutamine-mediated aggregation. J Cell Biol 1998; 143: 1457-70.

[89] Yoshizawa T, Yamagishi Y, Koseki N, et al. Cell cycle arrest enhances the in vitro cellular toxicity of the truncated MachadoJoseph disease gene product with an expanded polyglutamine stretch. Hum Mol Genet 2000; 9: 69-78.

[90] Breuer P, Haacke A, Evert BO, Wullner U. Nuclear aggregation of polyglutamine-expanded ataxin-3: fragments escape the cytoplasmic quality control. J Biol Chem 2010; 285: 6532-7.

[91] Warrick JM, Morabito LM, Bilen J, et al. Ataxin-3 suppresses polyglutamine neurodegeneration in Drosophila by a ubiquitinassociated mechanism. Mol Cell 2005; 18: 37-48.

[92] Warrick JM, Paulson HL, Gray-Board GL, et al. Expanded polyglutamine protein forms nuclear inclusions and causes neural degeneration in Drosophila. Cell 1998; 93: 939-49.

[93] Torashima T, Koyama C, Iizuka A, et al. Lentivector-mediated rescue from cerebellar ataxia in a mouse model of spinocerebellar ataxia. EMBO Rep 2008; 9:393-9.

[94] Konno A, Shuvaev AN, Miyake N, et al. Mutant ataxin-3 with an abnormally expanded polyglutamine chain disrupts dendritic development and metabotropic glutamate receptor signaling in mouse cerebellar Purkinje cells. Cerebellum 2014; 13: 29-41.

[95] Mendonca LS, Nobrega C, Hirai H, Kaspar BK, Pereira de Almeida L. Transplantation of cerebellar neural stem cells improves motor coordination and neuropathology in Machado-Joseph disease mice. Brain 2015; 138: 320-35

[96] Nascimento-Ferreira I, Nobrega C, Vasconcelos-Ferreira A, et al. Beclin 1 mitigates motor and neuropathological deficits in genetic mouse models of Machado-Joseph disease. Brain 2013; 136: 2173-88.

[97] Nobrega C, Nascimento-Ferreira I, Onofre I, et al. Silencing mutant ataxin-3 rescues motor deficits and neuropathology in Machado-Joseph disease transgenic mice. PLoS One 2013; 8: e52396.

[98] Ikeda F, Dikic I. Atypical ubiquitin chains: new molecular signals. 'Protein Modifications: Beyond the Usual Suspects' review series. EMBO Rep 2008; 9: 536-42.

[99] Almeida B, Fernandes S, Abreu IA, Macedo-Ribeiro S. Trinucleotide repeats: a structural perspective. Front Neurol 2013; 4: 76.

[100] Kayed R, Sokolov Y, Edmonds B, et al. Permeabilization of lipid bilayers is a common conformation-dependent activity of soluble amyloid oligomers in protein misfolding diseases. J Biol Chem 2004; 279: 46363-6.

[101] Demuro A, Mina E, Kayed R, Milton SC, Parker I, Glabe CG. Calcium dysregulation and membrane disruption as a ubiquitous neurotoxic mechanism of soluble amyloid oligomers. J Biol Chem 2005; 280: 17294-300.

[102] Schaffar G, Breuer P, Boteva R, et al. Cellular toxicity of polyglutamine expansion proteins: mechanism of transcription factor deactivation. Mol Cell 2004; 15: 95-105.

[103] Schaefer MH, Wanker EE, Andrade-Navarro MA. Evolution and function of $\mathrm{CAG} /$ polyglutamine repeats in protein-protein interaction networks. Nucleic Acids Res 2012; 40: 4273-87.

[104] Boeddrich A, Gaumer S, Haacke A, et al. An arginine/lysine-rich motif is crucial for $\mathrm{VCP} / \mathrm{p} 97$-mediated modulation of ataxin-3 fibrillogenesis. EMBO J 2006; 25: 1547-58.

[105] Doss-Pepe EW, Stenroos ES, Johnson WG, Madura K. Ataxin-3 interactions with rad23 and valosin-containing protein and its associations with ubiquitin chains and the proteasome are consistent with a role in ubiquitin-mediated proteolysis. Mol Cell Biol 2003; 23: 6469-83.

[106] Albrecht M, Golatta M, Wullner U, Lengauer T. Structural and functional analysis of ataxin-2 and ataxin-3. Eur J Biochem 2004; 271: 3155-70.

[107] Wang Q, Li L, Ye Y. Regulation of retrotranslocation by p97associated deubiquitinating enzyme ataxin-3. J Cell Biol 2006; 174: 963-71

[108] Zhong X, Pittman RN. Ataxin-3 binds VCP/p97 and regulates retrotranslocation of ERAD substrates. Hum Mol Genet 2006; 15 : 2409-20.

[109] Jana NR, Dikshit P, Goswami A, et al. Co-chaperone CHIP associates with expanded polyglutamine protein and promotes their degradation by proteasomes. J Biol Chem 2005; 280: 11635-40.

[110] Durcan TM, Fon EA. Ataxin-3 and its e3 partners: implications for machado-joseph disease. Front Neurol 2013; 4: 46.

[111] Durcan TM, Kontogiannea M, Thorarinsdottir T, et al. The Machado-Joseph disease-associated mutant form of ataxin-3 regulates parkin ubiquitination and stability. Hum Mol Genet 2011; 20: $141-54$.

[112] Mazzucchelli S, De Palma A, Riva M, et al. Proteomic and biochemical analyses unveil tight interaction of ataxin-3 with tubulin. Int J Biochem Cell Biol 2009; 41: 2485-92.

[113] Evert BO, Araujo J, Vieira-Saecker AM, et al. Ataxin-3 represses transcription via chromatin binding, interaction with histone deacetylase 3, and histone deacetylation. J Neurosci 2006; 26: 11474-86.

[114] Li F, Macfarlan T, Pittman RN, Chakravarti D. Ataxin-3 is a histone-binding protein with two independent transcriptional corepressor activities. J Biol Chem 2002; 277: 45004-12.

[115] Ferro A, Carvalho AL, Teixeira-Castro A, et al. NEDD8: a new ataxin-3 interactor. Biochim Biophys Acta 2007; 1773: 1619-27.

[116] Chai Y, Berke SS, Cohen RE, Paulson HL. Poly-ubiquitin binding by the polyglutamine disease protein ataxin-3 links its normal function to protein surveillance pathways. J Biol Chem 2004; 279: 3605-11.

[117] Nicastro G, Masino L, Esposito V, et al. Josephin domain of ataxin-3 contains two distinct ubiquitin-binding sites. Biopolymers 2009; 91: 1203-14

[118] Nicastro G, Todi SV, Karaca E, Bonvin AM, Paulson HL, Pastore A. Understanding the role of the Josephin domain in the PolyUb binding and cleavage properties of ataxin-3. PLoS One 2010; 5: e12430.

[119] Winborn BJ, Travis SM, Todi SV, et al. The deubiquitinating enzyme ataxin-3, a polyglutamine disease protein, edits Lys63 linkages in mixed linkage ubiquitin chains. J Biol Chem 2008; 283: 26436-43.

[120] Araujo J, Breuer P, Dieringer S, et al. FOXO4-dependent upregulation of superoxide dismutase-2 in response to oxidative stress is impaired in spinocerebellar ataxia type 3. Hum Mol Genet 2011; 20: $2928-41$

[121] Chou AH, Chen SY, Yeh TH, Weng YH, Wang HL. HDAC inhibitor sodium butyrate reverses transcriptional downregulation and ameliorates ataxic symptoms in a transgenic mouse model of SCA3. Neurobiol Dis 2011; 41: 481-8.

[122] Chou AH, Yeh TH, Kuo YL, et al. Polyglutamine-expanded ataxin-3 activates mitochondrial apoptotic pathway by upregulating Bax and downregulating Bcl-xL. Neurobiol Dis 2006; 21: 333-45.

[123] Chou AH, Yeh TH, Ouyang P, Chen YL, Chen SY, Wang HL. Polyglutamine-expanded ataxin-3 causes cerebellar dysfunction of SCA3 transgenic mice by inducing transcriptional dysregulation. Neurobiol Dis 2008; 31: 89-101. 
[124] Wen FC, Li YH, Tsai HF, et al. Down-regulation of heat shock protein 27 in neuronal cells and non-neuronal cells expressing mutant ataxin-3. FEBS Lett 2003; 546: 307-14.

[125] Evert BO, Vogt IR, Vieira-Saecker AM, et al. Gene expression profiling in ataxin-3 expressing cell lines reveals distinct effects of normal and mutant ataxin-3. J Neuropathol Exp Neurol 2003; 62: 1006-18.

[126] Tait D, Riccio M, Sittler A, et al. Ataxin-3 is transported into the nucleus and associates with the nuclear matrix. Hum Mol Genet 1998; 7: 991-7.

[127] Antony PM, Mantele S, Mollenkopf P, et al. Identification and functional dissection of localization signals within ataxin-3. Neurobiol Dis 2009; 36: 280-92.

[128] Hübener J, Vauti F, Funke C, et al. N-terminal ataxin-3 causes neurological symptoms with inclusions, endoplasmic reticulum stress and ribosomal dislocation. Brain 2011; 134: 1925-42.

[129] Nascimento-Ferreira I, Santos-Ferreira T, Sousa-Ferreira L, et al. Overexpression of the autophagic beclin-1 protein clears mutant ataxin-3 and alleviates Machado-Joseph disease. Brain 2011; 134: $1400-15$.

[130] Gales L, Cortes L, Almeida C, et al. Towards a structural understanding of the fibrillization pathway in Machado-Joseph's disease: trapping early oligomers of non-expanded ataxin-3. J Mol Biol 2005; 353: 642-54.

[131] Masino L, Nicastro G, Menon RP, Dal Piaz F, Calder L, Pastore A. Characterization of the structure and the amyloidogenic properties of the Josephin domain of the polyglutamine-containing protein ataxin-3. J Mol Biol 2004; 344: 1021-35.

[132] Masino L, Nicastro G, Calder L, Vendruscolo M, Pastore A. Functional interactions as a survival strategy against abnormal aggregation. FASEB J 2011; 25: 45-54.

[133] Saunders HM, Bottomley SP. Multi-domain misfolding: understanding the aggregation pathway of polyglutamine proteins. Protein Eng Des Sel 2009; 22: 447-51.

[134] Paulson HL, Das SS, Crino PB, et al. Machado-Joseph disease gene product is a cytoplasmic protein widely expressed in brain. Ann Neurol 1997; 41: 453-62.

[135] Nishiyama K, Murayama S, Goto J, et al. Regional and cellular expression of the Machado-Joseph disease gene in brains of normal and affected individuals. Ann Neurol 1996; 40: 776-81.

[136] La Spada AR, Taylor JP. Polyglutamines placed into context. Neuron 2003; 38: 681-4.

[137] Pennuto M, Palazzolo I, Poletti A. Post-translational modifications of expanded polyglutamine proteins: impact on neurotoxicity. Hum Mol Genet 2009; 18: R40-7.

[138] Chen X, Tang TS, Tu H, et al. Deranged calcium signaling and neurodegeneration in spinocerebellar ataxia type 3 . J Neurosci 2008; 28: 12713-24

[139] Nixon RA. The calpains in aging and aging-related diseases. Ageing Res Rev 2003; 2: 407-18.

[140] Evert BO, Wullner U, Schulz JB, et al. High level expression of expanded full-length ataxin-3 in vitro causes cell death and formation of intranuclear inclusions in neuronal cells. Hum Mol Genet 1999; 8: 1169-76.

[141] Rüb U, Brunt ER, Deller T. New insights into the pathoanatomy of spinocerebellar ataxia type 3 (Machado-Joseph disease). Curr Opin Neurol 2008; 21: 111-6.

[142] Gomez CM, Thompson RM, Gammack JT, et al. Spinocerebellar ataxia type 6: gaze-evoked and vertical nystagmus, Purkinje cell degeneration, and variable age of onset. Ann Neurol 1997; 42: 933-50.

[143] Ishikawa K, Watanabe M, Yoshizawa K, et al. Clinical, neuropathological, and molecular study in two families with spinocerebellar ataxia type 6 (SCA6). J Neurol Neurosurg Psychiatry 1999; 67: 86-9.

[144] Seidel K, Siswanto S, Brunt ER, den Dunnen W, Korf HW, Rub U. Brain pathology of spinocerebellar ataxias. Acta Neuropathol 2012; 124: 1-21.

[145] Zhuchenko O, Bailey J, Bonnen P, et al. Autosomal dominant cerebellar ataxia (SCA6) associated with small polyglutamine expansions in the alpha $1 \mathrm{~A}$-voltage-dependent calcium channel. Nat Genet 1997; 15: 62-9.

[146] Zamponi GW. Targeting voltage-gated calcium channels in neurological and psychiatric diseases. Nat Rev Drug Discov 2016; 15 : 19-34.
[147] Takahashi T, Momiyama A. Different types of calcium channels mediate central synaptic transmission. Nature 1993; 366: 156-8.

[148] Consortium GT. The Genotype-Tissue Expression (GTEx) project. Nat Genet 2013; 45: 580-5.

[149] Simms BA, Zamponi GW. Neuronal voltage-gated calcium channels: structure, function, and dysfunction. Neuron 2014; 82: 24-45.

[150] Westenbroek RE, Sakurai T, Elliott EM, et al. Immunochemical identification and subcellular distribution of the alpha 1A subunits of brain calcium channels. J Neurosci 1995; 15: 6403-18.

[151] UniProt C. UniProt: a hub for protein information. Nucleic Acids Res 2015; 43: D204-12.

[152] Jun K, Piedras-Renteria ES, Smith SM, et al. Ablation of P/Q-type $\mathrm{Ca}(2+)$ channel currents, altered synaptic transmission, and progressive ataxia in mice lacking the alpha(1A)-subunit. Proc Natl Acad Sci USA 1999; 96: 15245-50.

[153] Vecchia D, Tottene A, van den Maagdenberg AM, Pietrobon D. Abnormal cortical synaptic transmission in CaV2.1 knockin mice with the S218L missense mutation which causes a severe familial hemiplegic migraine syndrome in humans. Front Cell Neurosci 2015;9: 8 .

[154] Tottene A, Conti R, Fabbro A, et al. Enhanced excitatory transmission at cortical synapses as the basis for facilitated spreading depression in $\mathrm{Ca}(\mathrm{v}) 2.1$ knockin migraine mice. Neuron 2009; 61: $762-73$.

[155] Jen J, Wan J, Graves M, et al. Loss-of-function EA2 mutations are associated with impaired neuromuscular transmission. Neurology 2001; 57: 1843-8.

[156] Toru S, Murakoshi T, Ishikawa K, et al. Spinocerebellar ataxia type 6 mutation alters P-type calcium channel function. J Biol Chem 2000; 275: 10893-8.

[157] Saegusa H, Wakamori M, Matsuda Y, et al. Properties of human Cav2.1 channel with a spinocerebellar ataxia type 6 mutation expressed in Purkinje cells. Mol Cell Neurosci 2007; 34: 261-70.

[158] Watase K, Barrett CF, Miyazaki T, et al. Spinocerebellar ataxia type 6 knockin mice develop a progressive neuronal dysfunction with age-dependent accumulation of mutant CaV2.1 channels. Proc Natl Acad Sci USA 2008; 105: 11987-92.

[159] Ishikawa K, Fujigasaki H, Saegusa H, et al. Abundant expression and cytoplasmic aggregations of [alpha]1 A voltage-dependent calcium channel protein associated with neurodegeneration in spinocerebellar ataxia type 6. Hum Mol Genet 1999; 8: 1185-93.

[160] Ishiguro T, Ishikawa K, Takahashi M, et al. The carboxy-terminal fragment of alpha(1A) calcium channel preferentially aggregates in the cytoplasm of human spinocerebellar ataxia type 6 Purkinje cells. Acta Neuropathol 2010; 119: 447-64.

[161] Seidel K, Brunt ER, de Vos RA, et al. The p62 antibody reveals various cytoplasmic protein aggregates in spinocerebellar ataxia type 6. Clin Neuropathol 2009; 28: 344-9.

[162] Ishikawa K, Owada K, Ishida K, et al. Cytoplasmic and nuclear polyglutamine aggregates in SCA6 Purkinje cells. Neurology 2001; 56: 1753-6.

[163] Kordasiewicz HB, Thompson RM, Clark HB, Gomez CM. Ctermini of P/Q-type $\mathrm{Ca} 2+$ channel alpha1A subunits translocate to nuclei and promote polyglutamine-mediated toxicity. Hum Mol Genet 2006; 15: 1587-99.

[164] Kubodera T, Yokota T, Ohwada K, et al. Proteolytic cleavage and cellular toxicity of the human alpha1A calcium channel in spinocerebellar ataxia type 6 . Neurosci Lett 2003; 341: 74-8.

[165] Walker D, De Waard M. Subunit interaction sites in voltagedependent $\mathrm{Ca} 2+$ channels: role in channel function. Trends Neurosci 1998; 21: 148-54.

[166] Marqueze-Pouey B, Martin-Moutot N, Sakkou-Norton M, et al. Toxicity and endocytosis of spinocerebellar ataxia type 6 polyglutamine domains: role of myosin IIb. Traffic 2008; 9: 1088-100.

[167] Li L, Saegusa H, Tanabe T. Deficit of heat shock transcription factor 1-heat shock $70 \mathrm{kDa}$ protein $1 \mathrm{~A}$ axis determines the cell death vulnerability in a model of spinocerebellar ataxia type 6 . Genes Cells 2009; 14: 1253-69.

[168] Mark MD, Krause M, Boele HJ, et al. Spinocerebellar ataxia type 6 protein aggregates cause deficits in motor learning and cerebellar plasticity. J Neurosci 2015; 35: 8882-95.

[169] Takahashi M, Obayashi M, Ishiguro T, et al. Cytoplasmic location of alpha1A voltage-gated calcium channel C-terminal fragment (Cav2.1-CTF) aggregate is sufficient to cause cell death. PLoS One 2013; 8: e50121. 
[170] Du X, Wang J, Zhu H, et al. Second cistron in CACNA1A gene encodes a transcription factor mediating cerebellar development and SCA6. Cell 2013; 154: 118-33.

[171] Lebre AS, Brice A. Spinocerebellar ataxia 7 (SCA7). Cytogenet Genome Res 2003; 100: 154-63.

[172] David G, Abbas N, Stevanin G, et al. Cloning of the SCA7 gene reveals a highly unstable CAG repeat expansion. Nat Genet 1997; 17: 65-70

[173] Benton CS, de Silva R, Rutledge SL, Bohlega S, Ashizawa T, Zoghbi HY. Molecular and clinical studies in SCA-7 define a broad clinical spectrum and the infantile phenotype. Neurology 1998; 51: 1081-6.

[174] Giunti P, Stevanin G, Worth PF, David G, Brice A, Wood NW. Molecular and clinical study of 18 families with ADCA type II: evidence for genetic heterogeneity and de novo mutation. Am J Hum Genet 1999; 64: 1594-603.

[175] Cancel G, Duyckaerts C, Holmberg M, et al. Distribution of ataxin7 in normal human brain and retina. Brain 2000; $123 \mathrm{Pt} \mathrm{12:}$ 2519-30.

[176] Nakamura Y, Tagawa K, Oka T, et al. Ataxin-7 associates with microtubules and stabilizes the cytoskeletal network. Hum Mol Genet 2012; 21: 1099-110.

[177] Kaytor MD, Duvick LA, Skinner PJ, Koob MD, Ranum LP, Orr HT. Nuclear localization of the spinocerebellar ataxia type 7 protein, ataxin-7. Hum Mol Genet 1999; 8: 1657-64.

[178] Helmlinger D, Hardy S, Sasorith S, et al. Ataxin-7 is a subunit of GCN5 histone acetyltransferase-containing complexes. Hum Mol Genet 2004; 13: 1257-65.

[179] Zhao Y, Lang G, Ito S, et al. A TFTC/STAGA module mediates histone $\mathrm{H} 2 \mathrm{~A}$ and $\mathrm{H} 2 \mathrm{~B}$ deubiquitination, coactivates nuclear receptors, and counteracts heterochromatin silencing. Mol Cell 2008; 29: 92-101.

[180] Palhan VB, Chen S, Peng GH, et al. Polyglutamine-expanded ataxin-7 inhibits STAGA histone acetyltransferase activity to produce retinal degeneration. Proc Natl Acad Sci USA 2005; 102: 8472-7.

[181] Helmlinger D, Hardy S, Abou-Sleymane G, et al. Glutamineexpanded ataxin-7 alters TFTC/STAGA recruitment and chromatin structure leading to photoreceptor dysfunction. PLoS Biol 2006; 4: e67.

[182] Holmberg M, Duyckaerts C, Durr A, et al. Spinocerebellar ataxia type 7 (SCA7): a neurodegenerative disorder with neuronal intranuclear inclusions. Hum Mol Genet 1998; 7: 913-8.

[183] Mauger C, Del-Favero J, Ceuterick C, Lubke U, van Broeckhoven C, Martin J. Identification and localization of ataxin-7 in brain and retina of a patient with cerebellar ataxia type II using anti-peptide antibody. Brain Res Mol Brain Res 1999; 74: 35-43.

[184] Yvert G, Lindenberg KS, Picaud S, Landwehrmeyer GB, Sahel JA, Mandel JL. Expanded polyglutamines induce neurodegeneration and trans-neuronal alterations in cerebellum and retina of SCA7 transgenic mice. Hum Mol Genet 2000; 9: 2491-506.

[185] Garden GA, Libby RT, Fu YH, et al. Polyglutamine-expanded ataxin-7 promotes non-cell-autonomous purkinje cell degeneration and displays proteolytic cleavage in ataxic transgenic mice. $\mathrm{J}$ Neurosci 2002; 22: 4897-905

[186] Yu X, Ajayi A, Boga NR, Strom AL. Differential degradation of full-length and cleaved ataxin-7 fragments in a novel stable inducible SCA7 model. J Mol Neurosci 2012; 47: 219-33.

[187] Young JE, Gouw L, Propp S, et al. Proteolytic cleavage of ataxin-7 by caspase- 7 modulates cellular toxicity and transcriptional dysregulation. J Biol Chem 2007; 282: 30150-60.

[188] La Spada AR, Fu YH, Sopher BL, et al. Polyglutamine-expanded ataxin-7 antagonizes CRX function and induces cone-rod dystrophy in a mouse model of SCA7. Neuron 2001; 31: 913-27.

[189] Guyenet SJ, Mookerjee SS, Lin A, et al. Proteolytic cleavage of ataxin-7 promotes SCA7 retinal degeneration and neurological dysfunction. Hum Mol Genet 2015; 24: 3908-17.

[190] Mookerjee S, Papanikolaou T, Guyenet SJ, et al. Posttranslational modification of ataxin-7 at lysine 257 prevents autophagy-mediated turnover of an N-terminal caspase-7 cleavage fragment. J Neurosci 2009; 29: 15134-44

[191] Taylor J, Grote SK, Xia J, et al. Ataxin-7 can export from the nucleus via a conserved exportin-dependent signal. J Biol Chem 2006; 281: 2730-9.

[192] Chen S, Peng GH, Wang X, et al. Interference of Crx-dependent transcription by ataxin-7 involves interaction between the glu- tamine regions and requires the ataxin-7 carboxy-terminal region for nuclear localization. Hum Mol Genet 2004; 13: 53-67.

[193] Mushegian AR, Vishnivetskiy SA, Gurevich VV. Conserved phosphoprotein interaction motif is functionally interchangeable between ataxin-7 and arrestins. Biochemistry 2000; 39: 6809-13.

[194] Ansorge O, Giunti P, Michalik A, et al. Ataxin-7 aggregation and ubiquitination in infantile SCA7 with 180 CAG repeats. Ann Neurol 2004; 56: 448-52.

[195] Yakura H, Wakisaka A, Fujimoto S, Itakura K. Letter: Hereditary ataxia and HL-A. N Engl J Med 1974; 291: 154-5.

[196] Orr HT, Chung MY, Banfi S, et al. Expansion of an unstable trinucleotide CAG repeat in spinocerebellar ataxia type 1. Nat Genet 1993; 4: 221-6.

[197] Onodera Y, Aoki M, Tsuda T, et al. High prevalence of spinocerebellar ataxia type 1 (SCA1) in an isolated region of Japan. J Neurol Sci 2000; 178: 153-8.

[198] Whaley NR, Fujioka S, Wszolek ZK. Autosomal dominant cerebellar ataxia type I: a review of the phenotypic and genotypic characteristics. Orphanet J Rare Dis 2011; 6: 33

[199] Burk K, Globas C, Bosch S, et al. Cognitive deficits in spinocerebellar ataxia type 1, 2, and 3. J Neurol 2003; 250: 207-11.

[200] Servadio A, Koshy B, Armstrong D, Antalffy B, Orr HT, Zoghbi HY. Expression analysis of the ataxin-1 protein in tissues from normal and spinocerebellar ataxia type 1 individuals. Nat Genet 1995; 10: 94-8.

[201] Cvetanovic M, Rooney RJ, Garcia JJ, et al. The role of LANP and ataxin 1 in E4F-mediated transcriptional repression. EMBO Rep 2007; 8: 671-7.

[202] Rub U, Burk K, Timmann D, et al. Spinocerebellar ataxia type 1 (SCA1): new pathoanatomical and clinico-pathological insights. Neuropathol Appl Neurobiol 2012; 38: 665-80.

[203] Klement IA, Skinner PJ, Kaytor MD, et al. Ataxin-1 nuclear localization and aggregation: role in polyglutamine-induced disease in SCA1 transgenic mice. Cell 1998; 95: 41-53.

[204] Wadia NH, Swami RK. A new form of heredo-familial spinocerebellar degeneration with slow eye movements (nine families). Brain 1971; 94: 359-74.

[205] Imbert G, Saudou F, Yvert G, et al. Cloning of the gene for spinocerebellar ataxia 2 reveals a locus with high sensitivity to expanded CAG/glutamine repeats. Nat Genet 1996; 14: 285-91.

[206] Pulst SM, Nechiporuk A, Nechiporuk T, et al. Moderate expansion of a normally biallelic trinucleotide repeat in spinocerebellar ataxia type 2. Nat Genet 1996; 14: 269-76.

[207] Sanpei K, Takano H, Igarashi S, et al. Identification of the spinocerebellar ataxia type 2 gene using a direct identification of repeat expansion and cloning technique, DIRECT. Nat Genet 1996; 14: $277-84$

[208] Lastres-Becker I, Rub U, Auburger G. Spinocerebellar ataxia 2 (SCA2). Cerebellum 2008; 7: 115-24.

[209] Alonso E, Martinez-Ruano L, De Biase I, et al. Distinct distribution of autosomal dominant spinocerebellar ataxia in the Mexican population. Mov Disord 2007; 22: 1050-3.

[210] Sinha KK, Worth PF, Jha DK, et al. Autosomal dominant cerebellar ataxia: SCA2 is the most frequent mutation in eastern India. J Neurol Neurosurg Psychiatry 2004; 75: 448-52.

[211] Velazquez-Perez L, Rodriguez-Labrada R, Garcia-Rodriguez JC, Almaguer-Mederos LE, Cruz-Marino T, Laffita-Mesa JM. A comprehensive review of spinocerebellar ataxia type 2 in Cuba. Cerebellum 2011; 10: 184-98.

[212] Infante J, Combarros O, Volpini V, Corral J, Llorca J, Berciano J. Autosomal dominant cerebellar ataxias in Spain: molecular and clinical correlations, prevalence estimation and survival analysis. Acta Neurol Scand 2005; 111: 391-9.

[213] Leggo J, Dalton A, Morrison PJ, et al. Analysis of spinocerebellar ataxia types 1, 2, 3, and 6, dentatorubral-pallidoluysian atrophy, and Friedreich's ataxia genes in spinocerebellar ataxia patients in the UK. J Med Genet 1997; 34: 982-5.

[214] Magana JJ, Velazquez-Perez L, Cisneros B. Spinocerebellar ataxia type 2: clinical presentation, molecular mechanisms, and therapeutic perspectives. Mol Neurobiol 2013; 47: 90-104.

[215] Elden AC, Kim HJ, Hart MP, et al. Ataxin-2 intermediate-length polyglutamine expansions are associated with increased risk for ALS. Nature 2010; 466: 1069-75.

[216] Yokoshi M, Li Q, Yamamoto M, Okada H, Suzuki Y, Kawahara Y. Direct binding of Ataxin-2 to distinct elements in 3' UTRs pro- 
motes mRNA stability and protein expression. Mol Cell 2014; 55: 186-98.

[217] Koyano S, Uchihara T, Fujigasaki H, Nakamura A, Yagishita S, Iwabuchi K. Neuronal intranuclear inclusions in spinocerebellar ataxia type 2: triple-labeling immunofluorescent study. Neurosci Lett 1999; 273: 117-20.

[218] Huynh DP, Figueroa K, Hoang N, Pulst SM. Nuclear localization or inclusion body formation of ataxin-2 are not necessary for SCA2 pathogenesis in mouse or human. Nat Genet 2000; 26: 44-50.

[219] Turnbull VJ, Storey E, Tarlac V, et al. Different ataxin-2 antibodies display different immunoreactive profiles. Brain Res 2004; 1027: 103-16.

[220] Ng H, Pulst SM, Huynh DP. Ataxin-2 mediated cell death is dependent on domains downstream of the polyQ repeat. Exp Neurol 2007; 208: 207-15.

[221] Koide R, Kobayashi S, Shimohata T, et al. A neurological disease caused by an expanded CAG trinucleotide repeat in the TATAbinding protein gene: a new polyglutamine disease? Hum Mol Genet 1999; 8: 2047-53.

[222] Nakamura K, Jeong SY, Uchihara T, et al. SCA17, a novel autosomal dominant cerebellar ataxia caused by an expanded polyglutamine in TATA-binding protein. Hum Mol Genet 2001; 10: 1441-8.

[223] Stevanin G, Brice A. Spinocerebellar ataxia 17 (SCA17) and Huntington's disease-like 4 (HDL4). Cerebellum 2008; 7: 170-8.
[224] Rolfs A, Koeppen AH, Bauer I, et al. Clinical features and neuropathology of autosomal dominant spinocerebellar ataxia (SCA17). Ann Neurol 2003; 54: 367-75.

[225] van Roon-Mom WM, Reid SJ, Faull RL, Snell RG. TATA-binding protein in neurodegenerative disease. Neuroscience 2005; 133: 863-72.

[226] Vannini A, Cramer P. Conservation between the RNA polymerase I, II, and III transcription initiation machineries. Mol Cell 2012; 45: 439-46.

[227] Gao R, Matsuura T, Coolbaugh M, et al. Instability of expanded $\mathrm{CAG} / \mathrm{CAA}$ repeats in spinocerebellar ataxia type 17. Eur J Hum Genet 2008; 16: 215-22.

[228] Friedman MJ, Shah AG, Fang ZH, et al. Polyglutamine domain modulates the TBP-TFIIB interaction: implications for its normal function and neurodegeneration. Nat Neurosci 2007; 10: 1519-28.

[229] Friedman MJ, Wang CE, Li XJ, Li S. Polyglutamine expansion reduces the association of TATA-binding protein with DNA and induces DNA binding-independent neurotoxicity. J Biol Chem 2008; 283: 8283-90.

[230] Ordway JM, Cearley JA, Detloff PJ. CAG-polyglutamine-repeat mutations: independence from gene context. Philos Trans R Soc Lond B Biol Sci 1999; 354: 1083-8.

[231] Gipson TA, Neueder A, Wexler NS, Bates GP, Housman D. Aberrantly spliced HTT, a new player in Huntington's disease pathogenesis. RNA Biol 2013; 10: 1647-52. 